Federal Reserve Bank of Minneapolis

Research Department Staff Report 227

December 1996

\title{
Sticky Price and Limited Participation Models of Money: A Comparison
}

Lawrence J. Christiano*

Federal Reserve Banks of Chicago and Minneapolis, Northwestern University, and NBER

Martin Eichenbaum*

Northwestern University, Federal Reserve Bank of Chicago, and NBER

Charles L. Evans*

Federal Reserve Bank of Chicago

\begin{abstract}
We provide new evidence that models of the monetary transmission mechanism should be consistent with at least the following facts. After a contractionary monetary policy shock, the aggregate price level responds very little, aggregate output falls, interest rates initially rise, real wages decline by a modest amount, and profits fall. We compare the ability of sticky price and limited participation models with frictionless labor markets to account for these facts. The key failing of the sticky price model lies in its counterfactual implications for profits. The limited participation model can account for all the above facts, but only if one is willing to assume a high labor supply elasticity ( 2 percent) and a high markup (40 percent). The shortcomings of both models reflect the absence of labor market frictions, such as wage contracts or factor hoarding, which dampen movements in the marginal cost of production after a monetary policy shock.
\end{abstract}

*We are grateful for helpful discussions with V.V. Chari, Francesco Giavazzi, Christopher Sims, Tao Zha, and an anonymous referee. We thank Wendy Edelberg for superb research assistance. Christiano and Eichenbaum thank the National Science Foundation for financial support. The views expressed herein are those of the authors and not necessarily those of the Federal Reserve Banks of Chicago and Minneapolis or the Federal Reserve System. 


\section{Introduction}

Plausible models of the monetary transmission mechanism should be consistent with at least the following facts about the effects of a contractionary monetary policy shock:

- Aggregate price level initially responds very little.

- Aggregate output falls.

- Interest rates initially rise.

- Real wages decline by a modest amount.

- Profits fall.

In this paper, we provide new evidence to document these facts and we assess the ability of sticky price and limited participation models to account for them. A generic failing of the sticky price model is its implication that profits rise after a contractionary monetary policy shock. In contrast, the limited participation model is capable of accounting for all of the above facts, but only if one is willing to assume an implausibly high labor supply elasticity (e.g., 2 percent) and a high average markup (e.g., 40 percent). In our view, it is unlikely that any model which allows for only one type of friction will be able to account for all of the facts in a plausible way. But our results suggest that limited participation models are a more useful starting point than sticky price models.

To assess the effects of an exogenous shock to monetary policy, we use close variants of the policy shock measures developed in Christiano, Eichenbaum, and Evans (1996) and Sims and Zha (1995). Since the first three facts listed above are extensively documented in 
the literature, we focus the bulk of our empirical analysis on real wages and profits. Using both aggregate and sectoral data, we show that a contractionary monetary policy shock is associated with a small decline in real wages and a sharp, persistent drop in profits.

Based on our empirical analysis, we take as given the five facts listed above. We then turn to the question: What type of frictions are likely to be helpful in accounting for these facts? The first fact leads us to dismiss the Lucas (1972) model of money from consideration. This is because the engine driving the signaling problem at the core of that model is an immediate movement in the price level after a monetary policy shock. Such price movements are not observed in the postwar U.S. data. The fourth fact leads us to dismiss simple sticky wage models from consideration. Those types of models imply that real wages rise, not fall, after a contractionary monetary policy shock. ${ }^{1}$

In light of these considerations, we concentrate on two frictions that have received substantial attention in the recent literature. The first friction is that some firms do not immediately adjust prices in response to monetary policy shocks while ex post, output is demand determined. The effect of this friction is that aggregate output falls in response to a monetary contraction. The second friction is that households do not immediately adjust their nominal saving in response to monetary policy shocks. The effect of this friction is that monetary contractions disproportionately affect the reserves of banks and, hence, the supply of loanable funds. The result is a rise in interest rates which induces firms who need working capital to cut back on their scale of operations, and aggregate output declines.

\footnotetext{
${ }^{1}$ By simple sticky wage models we have in mind models which do not allow significant countercyclical markups. See Romer (1996, chap. 5.4) for further discussion.
} 
While these two frictions are by no means mutually exclusive, we find it useful to initially analyze them in isolation. We do this by considering separately, the consequences of introducing each of them into a single, benchmark model. ${ }^{2}$ The model economy is populated by an infinitely lived representative agent, a monetary authority, a competitive producer of final goods, and a continuum of intermediate good producers, each of whom are monopolists. In addition, there is a financial intermediary, which intermediates cash loans from households to intermediate good firms. The household purchases the final consumption good, supplies labor to intermediate good firms, and lends funds to the financial intermediary. The financial intermediary combines funds received from households with lump-sum injections of money from the government and makes loans to intermediate good firms. These firms need loans because they must pay labor costs before they sell their output. The size of the money transfers from the monetary authority to the financial intermediary is the only source of uncertainty in the model economy.

In the sticky price version of the model, the sequence of events within a period is as follows. First, intermediate good producers set their prices. Then the current-period money growth rate is realized. Finally, all other model variables are realized, with the output of the intermediate good producers being demand determined.

In the limited participation version of the model, goods prices are flexible, but we incorporate the second type of monetary friction discussed above. As in Lucas (1990), Christiano (1991), Fuerst (1992), and Christiano and Eichenbaum (1992, 1994, 1995), we do this by assuming that, in any given period, households must determine how much money to deposit

\footnotetext{
${ }^{2}$ Our benchmark model economy is closely related to the one considered by Blanchard and Kiyotaki (1987); Chari, Christiano, and Eichenbaum (1995); Chari, Kehoe, and McGrattan (1996); Cho and Cooley (1995); Ireland (1995); King and Watson (1996); Ohanian, Stockman, and Kilian (1995); and Woodford (1996).
} 
with financial intermediaries prior to the realization of the money shock.

We analyze how the model economies respond to an exogenous shock in the growth rate of money. Our findings can be summarized as follows. The key failing of the sticky price model is its implication that profits rise after a monetary contraction. This is true across a broad set of parameter values and perturbations of the model. The intuition is quite simple. Since output is demand determined, a monetary contraction leads to a substantial decline in the resources used by intermediate good producers. This, in the absence of labor market frictions or an extremely high elasticity of labor supply, leads to a substantial fall in wages and marginal costs, along with a sharp rise in the markup. Although revenues fall, cost considerations dominate and profits rise. We conclude that sticky prices alone are not sufficient to account for the key facts. Like Romer (1996, chap. 6.12), we suspect that labor market frictions, which have the effect of inhibiting cyclical movements in marginal costs by mimicking very high labor supply elasticities, need to be embedded in the current generation of general equilibrium sticky price models. ${ }^{3}$

We reach the same conclusion with the limited participation model, but the path by which we reach it is different. The limited participation model does at least as well, if not better, than the sticky price model. For this model, we find that if one is willing to assume a high labor supply elasticity (e.g., 2 percent) and a reasonably high markup (e.g., 40 percent), then the limited participation model can account for all of the stylized facts we stress above. Specifically, a contractionary shock to the growth rate of money has

\footnotetext{
${ }^{3}$ Romer (1996) argues his case in a different, but related way. He shows in a particular class of model economies that absent labor market frictions, what he views as implausibly large menu costs, are required to rationalize the sticky price assumption. The logic of his argument, like ours, focuses on the response of firms' marginal costs to monetary shocks.
} 
essentially no contemporaneous impact on the price level and drives wages, profits, output, and employment down, while driving the rate of interest up. But if one is not willing to accept high markups and labor supply elasticities, then the model has difficulty in generating a large output effect and a small price effect from a monetary policy shock. As with the sticky price models, it seems important to embed labor market frictions, which have the effect of mimicking a high elasticity of labor supply into the current generation of limited participation models. We conclude that general equilibrium models which allow for only one type of friction cannot convincingly account for the salient facts about how the economy responds to an unanticipated monetary policy shock.

The previous remarks may seem to suggest that we could remedy the shortcomings of the limited participation model by requiring a subset of the intermediate good firms to set their price in advance. However, we find that this change has only a relatively small impact on the equilibrium price and output response to a monetary policy shock. This is true even when as many as 80 percent of the intermediate good firms set their price in advance. The basic reason is as follows. For the subset of the firms who set prices in advance, the output effect of a contractionary policy shock is greater than in the equilibrium when all firms set prices flexibly. But the large drop in employment of labor and capital by fixed price firms leads to a large drop in the marginal cost of production. This in turn leads flexible price firms to drop their prices by a large amount and to actually increase output. This effect accounts for the small impact on aggregate price and output dynamics of the introduction of price setters and operates through the general equilibrium impact of a monetary shock on marginal costs. This basic result holds, even if there is limited mobility of capital and labor between the fixed and sticky price sectors of the economy. We conclude that embedding labor 
market frictions in the limited participation model is likely to prove a more fruitful way of remedying its shortcomings than allowing for sticky prices.

The finding that flexible price setters adjust their prices by more, the larger is the fraction of firms which fix prices in advance, also holds in a version of the sticky price model in which only a fraction of the firms set prices in advance. In our view, this finding calls into question the basic appeal of the sticky price model. Presumably, the appeal of that model rests on the notion that flexible price firms act more like fixed price firms the larger is the fraction of the firms in the economy who set their price in advance. The opposite is true for the environments that we consider. ${ }^{4}$

The remainder of this paper is organized as follows. In Section 2, we discuss the monetary policy shocks used in our empirical analysis and present our empirical results. In Section 3, we present the theoretical models. In Sections 4 and 5, we discuss qualitative and quantitative properties of the models, respectively. Our concluding remarks appear in Section 6 .

\section{The Empirical Effects of Monetary Policy Shocks}

\section{A. Policy Shock Measures}

In our empirical analysis, we use two measures of shocks to monetary policy. These are close variants of measures developed in Christiano, Eichenbaum, and Evans (1996) (CEE) and Sims and Zha (1995) (SZ). Both procedures posit that the Federal Reserve System follows

\footnotetext{
${ }^{4}$ These considerations suggest changing our environment to allow for factors which increase complementarity among price setters. This could, for example, be achieved by assuming that intermediate good producers use the output of other intermediary good producers as inputs to production. (See Basu (1995).) It would be of interest to explore the implications of this model modification in our environment. However, experiments reported in Chari, Kehoe, and McGrattan (1996) suggest that the gains from this modification may not be large.
} 
an interest rate targeting rule and that the monetary policy shock is a disturbance to that rule. They differ on the assumptions made to identify that shock.

\section{Christiano, Eichenbaum, and Evans Policy Shocks}

CEE identify a monetary policy shock with the disturbance term in the following interest rate targeting rule:

(1) $\quad R_{t}=\psi\left(\Omega_{t}\right)+\varepsilon_{s t}$

where $R_{t}$ is the federal funds rate, $\psi$ is a linear function, $\Omega_{t}$ summarizes the information available to the monetary authority when $R_{t}$ is set, and $\varepsilon_{s t}$ is a serially uncorrelated shock that is orthogonal to the elements of $\Omega_{t}$. (CEE also work with a version of (1), where $R_{t}$ is replaced by a measure of the nonborrowed reserves of banks.) The orthogonality restriction on $\varepsilon_{s t}$ corresponds to a particular recursiveness assumption: the monetary policy variable, $R_{t}$, is contemporaneously affected by the date $t$ variables in $\Omega_{t}$, but those variables are not contemporaneously affected by the monetary policy shock. The advantage of this recursiveness assumption is that it justifies estimating $\varepsilon_{s t}$ as the residual in an ordinary least squares regression of $R_{t}$ on $\Omega_{t}$. The impulse response of a variable to a policy shock can be measured by the coefficients in the regression of the variable on current and lagged values of the fitted residuals in (1).

In practice, we estimate the impulse response functions by an asymptotically equivalent procedure based on a Vector Autoregressive Representation (VAR) for a vector of variables, $Z_{t}$. (For the details of this procedure, see CEE.) In our benchmark VAR, $Z_{t}$ includes the log of real GDP, the log of the GDP deflator, an index of the change in sensitive commodity 
prices, the federal funds rate, the log of nonborrowed reserves, the log of total reserves, and the first difference of the log of M2. We structure the VAR so that it captures the CEE recursiveness assumption, and specifies that the contemporaneous variables in $\Omega_{t}$ are the first three variables in $Z_{t}$. The rationale for this specification is discussed in CEE. To assess the effect of a monetary policy shock on real wages, we add the log of real wages to $Z_{t}$. To assess the effect of a policy shock on the share of profits in output, we add the ratio of profits to nominal GNP to $Z_{t}$. We exclude contemporaneous real wages and the ratio of profits to nominal GNP from $\Omega$. The estimation period is from $1965 \mathrm{Q} 3$ to $1995 \mathrm{Q} 2$, and the VARs have a lag length of four. (See Appendix A for a detailed description of the data.)

\section{Sims-Zha Policy Shocks}

Although the recursiveness assumption implicit in the CEE procedure buys considerable simplicity, it may come at the cost of specification error. For this reason, we also consider SZ policy shocks, which do not make the recursiveness assumption. The cost, however, is that SZ must identify a broader set of economic relationships than do CEE, and these additional identifying assumptions could also entail specification error. For example, SZ assume that contemporaneous output does not enter the monetary policy rule, but it does enter the money demand equation. (See Appendix B for further details.)

SZ assume a monetary policy rule of the form

(2) $\quad R_{t}=g\left(\Theta_{t}\right)+\varepsilon_{s t}$.

Here, $g$ is a linear function, and $\Theta_{t}$ summarizes the variables that the policymakers look at when setting the target interest rate, $R_{t}$. SZ identify $R_{t}$ with the three-month rate of return 
on Treasury bills. The information set, $\Theta_{t}$, is composed of time $t$ values of crude materials prices and M2, and lagged values of the Treasury bill rate, intermediate materials prices, the aggregate price level, real wages, aggregate output, crude materials prices, M2, and a measure of personal bankruptcies.

Under SZ's assumptions, all of the variables in $Z_{t}$ can respond contemporaneously to a monetary policy shock. Because the monetary policy shock is not orthogonal to the elements of $\Theta_{t}$, it cannot be identified with the residuals in a least squares regression of $R_{t}$ on the elements of $\Theta_{t}$. The exact SZ procedure for identifying the policy shock is summarized in Appendix B. The associated impulse response functions are estimated using standard VAR methods. As in SZ, our VAR has four lags, and the estimation period is the same as for the CEE system.

Our version of SZ does not include their measure of personal bankruptcies, since we did not have access to this data. In addition, we work with the first difference of the log of M2. We do this to facilitate comparisons with the CEE results. In addition, we do not impose the overidentifying restrictions used by SZ that the demand for real balances has a coefficient of one on contemporaneous real income. ${ }^{5}$ To assess the effect of a monetary policy shock on the ratio of profits to nominal GNP, we amend the SZ system in a way that is summarized in Appendix B.

\section{B. The Effects of Monetary Policy Shocks on Wages and Profits}

In this section, we report the effects of a contractionary monetary policy shock on real wages and corporate profits. To help assess the properties of our benchmark policy

\footnotetext{
${ }^{5}$ Comparing the estimated dynamic response functions to a monetary shock in our benchmark system with those in SZ, it can be verified that these three perturbations make very little difference to the results.
} 
shock measures, Figure 1 displays the effects of contractionary benchmark CEE and SZ policy shocks on various economic aggregates. Solid lines report point estimates of dynamic response functions. Dashed lines denote a 95 percent confidence interval for the dynamic response functions. ${ }^{6}$ Since close variants of these response functions are discussed in CEE and SZ, we comment on them only briefly here.

The main consequences of a contractionary benchmark CEE policy shock can be summarized as follows. First, there is a persistent rise in the federal funds rate and a persistent drop in nonborrowed reserves and the growth rate of M2. After a one-quarter delay, the shock also leads to a persistent decline in total reserves. Second, after a delay of two quarters, there is a sustained decline in real GDP. ${ }^{7}$ Third, after an initial delay, the policy shock generates a persistent decline in the index of commodity prices. The GDP deflator is flat for roughly a year and a half before it declines. Fourth, we cannot reject the hypothesis that a monetary

\footnotetext{
${ }^{6}$ The 95 percent confidence intervals for the CEE impulse response functions in Figures 1-8 are computed using the following bootstrap Monte Carlo procedure. We first construct 1000 time series on the vector $Z_{t}$, each of length $T$, where $T$ denotes the number of observations in our data sample. Let $\left\{\widehat{u}_{t}\right\}_{t=1}^{T}$ denote the vector of residuals from the estimated VAR. We construct 1000 sets of new time series of residuals, $\left\{\widehat{u}_{t}(j)\right\}_{t=1}^{T}, j=1, \ldots, 1000$. The $t^{t h}$ element of $\left\{\widehat{u}_{t}(j)\right\}_{t=1}^{T}$ is selected by drawing randomly, with replacement, from the set of fitted residual vectors, $\left\{\widehat{u}_{t}\right\}_{t=1}^{T}$. For each $\left\{\widehat{u}_{t}(j)\right\}_{t=1}^{T}$, we construct a synthetic time series of $Z_{t}$, denoted $\left\{Z_{t}(j)\right\}_{t=1}^{T}$, using the estimated VAR and the historical initial conditions on $Z_{t}$. Second, we reestimate our VAR using $\left\{Z_{t}(j)\right\}_{t=1}^{T}$ and the historical initial conditions and calculate the implied impulse response functions for $j=1, \ldots, 1000$. For each fixed lag, we calculated the $25^{\text {th }}$ lowest and $975^{\text {th }}$ highest value of the corresponding impulse response coefficient across all 1000 synthetic impulse response functions. The boundaries of the confidence intervals in the figures correspond to a graph of these coefficients. The solid line reports our point estimate of the impulse response function. For the most part, these point estimates are quite similar to the mean value of the simulated impulse response functions. There is some evidence of bias, especially in Figure 7, which displays the results for our aggregate measures of profits. Interestingly, the evidence of bias suggests that our point estimates understate the magnitude of the drop in profits after a monetary contraction.

The bands for the SZ impulse response functions are computed using the procedure described in Sims and Zha (1995a). The reported bands are two standard deviations about the mean of the impulses. As in the case of $\mathrm{CEE}$, the solid line reports our point estimate of the impulse response function.

${ }^{7}$ The asymmetry in the confidence bands suggests that our estimate of the response of GDP to a monetary policy shock is biased toward zero. Thus, a bias-adjusted estimator would indicate a stronger negative response of GDP to a contractionary monetary policy shock. The same is true for the response of aggregate profits to a monetary policy shock. (See Figure 7.)
} 
policy shock has no effect on real balances in the long run.

The main consequences of a contractionary benchmark SZ policy shock can be summarized as follows. First, there is a persistent decline in the growth rate of M2 and a rise in the interest rate. Second, there is a persistent decline in the GDP deflator and the prices of intermediate goods and crude materials. Third, after a delay, the shock generates a persistent decline in real GDP. Finally, note that the benchmark measure of real wages (average hourly earnings of private nonagricultural production workers divided by the GDP deflator) is basically unaffected by the SZ policy shock. Overall, the qualitative response of the system to a policy shock is quite similar for the $\mathrm{CEE}$ and $\mathrm{SZ}$ policy shock measures. However, the estimated SZ policy shocks are somewhat smaller than the estimated CEE policy shocks. For example, the impact effect of a CEE policy shock on the federal funds rate is about 70 basis points, while the impact of a SZ policy shock on the three-month Treasury bill rate is about 40 basis points. In addition, the impulse response functions associated with the SZ policy shocks are estimated somewhat less precisely than the ones associated with the CEE policy shocks.

Figure 2 reports the response of different measures of real wages to contractionary $\mathrm{CEE}$ and SZ policy shocks. Rows 1-6 report the response of five measures of aggregate real wages: (1) the benchmark measure we discuss above, (2) average hourly earnings of production workers in the private nonagricultural sector deflated by the Bureau of Labor Statistics using an index derived from the Consumer Price Index for Urban Wage Earners and Clerical Workers, (3) average hourly earnings of production workers in the manufacturing sector divided by the GDP deflator, (4) average hourly earnings of production workers in the manufacturing durable goods sector divided by the GDP deflator, and (5) average hourly 
earnings of production workers in the manufacturing nondurable goods sector divided by the GDP deflator.

The key results can be summarized as follows. First, with two exceptions, regardless of which policy shock or which measure of real wages we work with, according to the point estimates, a contractionary monetary policy shock leads to a persistent decline in real wages. The exceptions are that measures (1) and (5) of real wages appear roughly unaffected by a SZ policy shock. Second, for both policy shock measures, manufacturing real wages fall more sharply than economywide wage measures. Finally, within manufacturing, real wages fall more sharply in the durable good industries than in the nondurable good industries. Generally speaking, the decline in real wages following a SZ policy shock is smaller and less precisely estimated than the decline following a CEE policy shock.

Next, we consider the response of real wages at the two-digit SIC industry level to a contractionary policy shock, where real wages are measured as gross average hourly earnings of production and nonsupervisory workers deflated by the GDP deflator. Figure 3 reports the response of real wages to a contractionary CEE policy shock for 10 two-digit SIC code nondurable good industries. ${ }^{8}$ Figure 4 reports the analog results for a contractionary SZ policy shock. Figure 5 reports the response of real wages to a contractionary CEE policy shock for 10 two-digit SIC code durable good industries. ${ }^{9}$ Figure 6 reports the analog results for a SZ policy shock.

\footnotetext{
${ }^{8}$ Food and Kindred Products, SIC 20; Tobacco, SIC 21; Textile Mill Products, SIC 22; Apparel and Other Textiles, SIC 23; Paper and Allied Products, SIC 26; Printing and Publishing, SIC 27; Chemicals and Allied Products, SIC 28; Petroleum and Coal, SIC 29; Rubber and Miscellaneous Plastic Products, SIC 30; and Leather and Leather Products, SIC 31.

${ }^{9}$ Lumber and Wood Products, SIC 24; Furniture and Fixtures, SIC 25; Stone, Clay, and Glass, SIC 32; Primary Metal Industries, SIC 33; Fabricated Metal Industries, SIC 34; Machinery-Except Electrical, SIC 35; Electric and Electronic Equipment, SIC 36; Transportation Equipment, SIC 37; Instruments and Related Products, SIC 38; and Miscellaneous Manufacturing, SIC 39.
} 
The key results can be summarized as follows. First, real wages in all but one of each of the nondurable and durable good industries (leather and leather products, and instruments and related products, respectively) fall after a contractionary CEE policy shock. Second, the declines are greater in the durable good industries than in the nondurable good industries. Third, for both industries, the results are more mixed for the SZ policy shock measure.

Integrating across all of our results, we conclude there is substantial evidence in support of the view that real wages fall in response to a contractionary monetary policy shock. There is no evidence to support the view that real wages rise in response to such a shock.

We now discuss the response of profits to a monetary policy shock. Figure 7 reports the response of seven different measures of profits to contractionary CEE and SZ policy shocks: (1) total before-tax profits, (2) total after-tax profits, (3) net domestic profits after taxes, (4) nonfinancial net domestic after-tax profits, (5) total after-tax profits net of interest costs, (6) net after-tax domestic profits net of interest costs, and (7) nonfinancial after-tax domestic profits net of interest costs. The last three measures of profits are of some interest because they allow us to isolate the role that interest rate costs play in the response of profits to a contractionary policy shock. Notice that regardless of which measure we work with, both CEE and SZ contractionary monetary policy shocks lead to a persistent decline in profits. This is true even when we construct profits in a way that does not take into account interest costs. The dynamic impulse response functions of $\mathrm{SZ}$ are estimated less precisely than in the case of CEE.

Next, we consider the response of profits at the sectoral level to contractionary CEE and SZ policy shocks. Figure 8 reports the response of before-tax profits in five sectors of the economy: manufacturing, nondurables, durables, retail, and transportation and utilities. As 
above, profits are calculated as a fraction of nominal GDP. Notice that for the CEE policy shock measures, profits in manufacturing, durable goods, and the retail sector experience persistent drops after a contractionary policy shock. This is not true for nondurable goods and transportation and utilities. While profits appear to rise in these industries, one cannot reject the hypothesis that profits are unaffected by the policy shock. The results with the SZ policy shock measures are consistent with those of the CEE policy shock measures, although again the dynamic response functions are estimated less precisely. Figures 7 and 8 provide strong evidence that profits fall after a contractionary policy shock.

Based on the evidence reported in this section, we conclude that business cycle models ought to have the implication that output, real wages, and profits fall in response to a contractionary policy shock. For a substantial period of time, the aggregate price level should not respond. While there is uncertainty about the response of real wages, plausible theories will not have the implication that real wages rise after a contractionary policy shock.

\section{Our Sticky Price and Limited Participation Models}

In this section, we describe our fixed price and limited participation models, which correspond to two specifications of the sequence of events in a basic, benchmark model. We first present the problems faced by the agents in our model, and we then discuss our equilibrium concept.

\section{A. Final Good Firms}

At time $t$, a final consumption good, $Y_{t}$, is produced by a perfectly competitive firm. The firm does so by combining a continuum of intermediate goods, indexed by $i \in(0,1)$, 
using the technology

(3) $\quad Y_{t}=\left[\int_{0}^{1} Y_{i t^{\frac{1}{\mu}}} d i\right]^{\mu}$

where $1 \leq \mu<\infty$, and $Y_{i t}$ denotes the time $t$ input of intermediate good $i$. Let $P_{t}$ and $P_{i t}$ denote the time $t$ price of the consumption good and intermediate good $i$, respectively. Profit maximization implies the Euler equation

(4) $\quad\left(\frac{P_{t}}{P_{i t}}\right)^{\frac{\mu}{\mu-1}}=\frac{Y_{i t}}{Y_{t}}$.

According to (4), the demand for intermediate good $i$ is a decreasing function of the relative price of that good and an increasing function of aggregate output, $Y_{t}$. Integrating (4) and imposing (3), we obtain the following relationship between the price of the final good and the price of the intermediate good:

(5) $\quad P_{t}=\left[\int_{0}^{1} P_{i t}^{\frac{1}{1-\mu}} d i\right]^{(1-\mu)}$.

\section{B. Intermediate Good Firms}

Intermediate good $i$ is produced by a monopolist who uses the following technology:

(6) $\quad Y_{i t}= \begin{cases}K_{i t}^{\alpha} N_{i t}^{1-\alpha}-\phi & \text { if } K_{i t}^{\alpha} N_{i t}^{1-\alpha} \geq \phi \\ 0, & \text { otherwise }\end{cases}$

where $0<\alpha<1$. Here, $N_{i t}$ and $K_{i t}$ denote time $t$ labor and capital used to produce the $i^{t h}$ intermediate good. The parameter $\phi$ denotes a fixed cost of production. We rule out entry and exit into the production of intermediate good $i$.

Intermediate firms rent capital and labor in perfectly competitive factor markets. Economic profits are distributed to the firms' owner, the representative household, at the beginning of time period $t+1$. We denote the time $t$ rental rate on capital and the wage rate 
by $r_{t}$ and $W_{t}$, respectively. Workers must be paid in advance of production. As a result, firms need to borrow their wage bill, $W_{t} N_{i t}$, from the financial intermediary at the beginning of the period. Repayment occurs at the end of time period $t$ at the gross interest rate, $R_{t}$. Consequently, the firm's total time $t$ costs are given by $R_{t} W_{t} N_{i t}+r_{t} K_{i t}$. Their cost function is given by

$$
C\left(r_{t}, R_{t} W_{t}, Y_{i t}\right)=A\left(r_{t}\right)^{\alpha}\left(W_{t} R_{t}\right)^{1-\alpha}\left(Y_{i t}+\phi\right)
$$

where $A=\left(\frac{1}{1-\alpha}\right)^{(1-\alpha)}\left(\frac{1}{\alpha}\right)^{\alpha}$, so that the time $t$ marginal cost of producing additional output, given $Y_{i t}>0$, is $M C\left(r_{t}, R_{t} W_{t}\right)=A r_{t}^{\alpha}\left(W_{t} R_{t}\right)^{1-\alpha}$. A convenient representation of this expression, which holds in equilibrium, is given by

$$
M C\left(r_{t}, R_{t} W_{t}\right)=\frac{1}{1-\alpha} N_{t}^{\alpha} W_{t} R_{t}
$$

where $N_{t}$ denotes aggregate employment, and we take into account our assumption that the aggregate stock of capital is a constant, unity. ${ }^{10}$

In the version of the model where prices are set flexibly, profit maximization leads the intermediate good firm to set its price equal to a constant markup over marginal cost:

(9) $\quad P_{i t}=\mu M C_{t}$.

In the version of the model where the firm sets its price prior to the realization of the money shock, it does so to optimize the appropriately weighted expectation of profits:

(10) $\quad E_{t-1} \frac{U_{c, t+1}}{P_{t+1}}\left[P_{i t} Y_{i t}-C\left(r_{t}, R_{t} W_{t}, Y_{i t}\right)\right]$

\footnotetext{
${ }^{10} \mathrm{To}$ obtain this expression, we note that an efficiency condition of firm $i \in(0,1)$ is $r_{t} /\left(W_{t} R_{t}\right)=$ $[\alpha /(1-\alpha)] N_{i t} / K_{i t}$. The implied equality of firm labor-to-capital ratios implies that this expression holds for the aggregate ratio of labor to capital; $N_{t} / K_{t}$. To obtain (8), we substitute this expression with the aggregate variables into $A r_{t}^{\alpha}\left(W_{t} R_{t}\right)^{1-\alpha}$ and take into account the equilibrium condition, $K_{t}=1$.
} 
subject to the demand equation, (4). Here, $U_{c, t+1}$ denotes the time $t+1$ marginal utility of the representative household. The $i^{\text {th }}$ intermediate good firm takes prices and quantities other than $P_{i t}$ and $Y_{i t}$ as given and beyond its control. The weights on profits in (10) correspond to the marginal utility of a dollar to the firm's owner, the representative household, and the dating reflects our assumption (displayed below) that the household cannot spend its date $t$ profits until date $t+1$. Under these circumstances, the firm is led to set its price equal to a constant markup over a weighted expectation of marginal cost:

$$
P_{i t}=\mu E_{t-1} \omega_{t} M C_{t}
$$

where

$$
\omega_{t}=\frac{\left[E_{t} \frac{U_{c, t+1}}{P_{t+1}}\right] P_{t}^{\frac{\mu}{\mu-1}} Y_{t}}{E_{t-1}\left[\frac{U_{c, t+1}}{P_{t+1}} P_{t}^{\frac{\mu}{\mu-1}} Y_{t}\right]}
$$

As (12) makes clear, in setting its price, the firm places a great deal of weight on $M C_{t}$ in states of the world where aggregate demand, $Y_{t}$, is large.

Expressions (4), (9), and (11) indicate that in equilibrium, $N_{i t}=N_{t}, K_{i t}=K_{t}$, $Y_{i t}=Y_{t}$, and $P_{i t}=P_{t}$, for $i \in(0,1)$. Note that although final goods are priced flexibly, in equilibrium they inherit whatever inflexibility there is in intermediate good prices. (See (5).)

\section{Financial Intermediary}

At time $t$, a perfectly competitive financial intermediary receives deposits, $I_{t}$, from the household and lump-sum cash injections, $X_{t}$, from the monetary authority. These funds are supplied to the loan market at the gross interest rate, $R_{t}$. Demand in the loan market comes from the intermediary good producers who seek to finance their wage bill, $W_{t} N_{t}$. Loan 
market clearing requires

$$
W_{t} N_{t}=I_{t}+X_{t}
$$

At the end of the period, the intermediary pays $R_{t} I_{t}$ to households in return for their deposits and distributes $R_{t} X_{t}$ to households in the form of profits.

\section{Households}

At time $t$, the representative household ranks alternative streams of consumption and hours worked according to the criterion function:

$$
E_{t} \sum_{j=0}^{\infty} \beta^{j} U\left(C_{t+j}, N_{t+j}\right)
$$

Here, $0<\beta<1, C_{t}$ denotes time $t$ units of consumption, $N_{t}$ denotes time $t$ hours of work, and

$$
U(C, N)=\log \left[C-\frac{\psi_{0}}{1+\psi} N^{1+\psi}\right]
$$

In (15), $\psi_{0}>0$, and $\psi>0$. Specification (15) has the convenient feature that the household has a well-defined static labor supply function, whose elasticity, $1 / \psi$, is a constant. ${ }^{11}$ In our quantitative analysis, we also consider an alternative specification of utility.

${ }^{11}$ It may seem that (15) is difficult to reconcile with balanced growth. We can reconcile our model with balanced growth as follows. First, we think of (15) as the indirect utility function for a household whose actual utility function is

$$
\log \left(C+C_{n}\right)-\gamma \log \left(\frac{N^{1+\psi}}{1+\psi}+N_{n}\right)
$$

where $N_{n}$ and $C_{n}$ denote nonmarket hours worked and consumption, respectively. Second, suppose the home production function is $C_{n}=\psi_{0} N_{n}$. Proceeding as in Benhabib, Rogerson, and Wright (1991), it is straightforward to show that the indirect utility function in $C$ and $N$ is

$$
\log \left(\frac{1}{1-\gamma}\right)-\gamma \log \left(\frac{\gamma}{\psi_{0}(1-\gamma)}\right)+(1-\gamma) \log \left(C-\psi_{0} \frac{N^{1+\psi}}{1+\psi}\right)
$$

We get a balanced growth path in which labor does not grow, and all other quantities grow at a positive rate by assuming that intermediate good firm technologies and the home production function shift up at the same, constant rate. 
The household is endowed with $K_{t}$ units of capital, which it supplies inelastically to a competitive rental market in which the rental rate is denoted by $r_{t}$. To simplify the analysis, we assume there exists no technology for increasing the aggregate stock of capital and that the rate of depreciation is zero. As a result, the per capita stock of capital is a constant, and we specify this to be unity. We assume there is no market in which agents can trade ownership claims on capital. This is without loss of generality, since we assume all agents are identical.

The household supplies $N_{t}$ units of labor at the nominal wage rate, $W_{t}$, and faces the following cash constraint on its consumption purchases:

$$
P_{t} C_{t} \leq W_{t} N_{t}+M_{t}-I_{t}
$$

Here, $M_{t}$ denotes the household's beginning-of-period $t$ holdings of cash, and $I_{t}$ denotes time $t$ dollars sent to the financial intermediary. Constraint (16) implies that time period $t$ wage earnings are payable to the household in time to satisfy its time $t$ cash constraint. The household's money holdings evolve according to

$$
M_{t+1}=\left[W_{t} N_{t}+M_{t}-I_{t}-P_{t} C_{t}\right]+r_{t} K_{t}+R_{t}\left[I_{t}+X_{t}\right]+D_{t}
$$

where $D_{t}$ and $R_{t} X_{t}$ denote time $t$ profits received from intermediate good producers and financial intermediaries, respectively.

The household maximizes (14), subject to (15)-(17). In both versions of the model, $C_{t}, N_{t}$, and $M_{t+1}$ are chosen after the realization of the time $t$ monetary shock. This is also true for $I_{t}$ in the fixed price model. In the limited participation version of the model, $I_{t}$ is set before the realization of the period $t$ monetary shock. 
The first-order-necessary condition associated with the household's choice of $N_{t}$ is given by

$$
\frac{W_{t}}{P_{t}}=\psi_{0} N_{t}^{\psi}
$$

In the sticky price version of the model, the Euler equation for $I_{t}$ is given by

$$
\frac{U_{c, t}}{P_{t}}=R_{t} E_{t} \frac{\beta U_{c, t+1}}{P_{t+1}}
$$

According to (19), the household equates the marginal utility of a dollar deposited with the financial intermediary at time $t$ to the time $t+1$ expected marginal utility of the returns from that deposit. In the limited participation version of the model, the Euler equation for $I_{t}$ is given by

(20) $E_{t-1} \frac{U_{c, t}}{P_{t}}=E_{t-1} R_{t} \frac{\beta U_{c, t+1}}{P_{t+1}}$.

\section{E. Monetary Authority}

We assume that the growth rate of money, $x_{t} \equiv X_{t} / M_{t}=\left(M_{t+1}-M_{t}\right) / M_{t}$, is the realization of an exogenous, three-state Markov chain with an unconditional mean growth rate of $\mu_{x}$. We discuss the details of this process in the next subsection. There, we also discuss the relationship between the representation of monetary policy used in the model and the interest rate targeting representation we adopt in our empirical analysis.

\section{F. Equilibrium and Computation}

Let $Z_{t}$ denote the vector of nominal variables (excluding $R_{t}$ ) scaled by the beginningof-period stock of money. Let $Q_{t}$ denote the other variables. Thus,

$$
Z_{t}=\left[P_{i t}, P_{t}, W_{t}, r_{t}, I_{t}, X_{t}\right] / M_{t}, Q_{t}=\left[R_{t}, C_{t}, Y_{t}, Y_{i t}, K_{i t}, K_{t}, N_{t}, N_{i t},\right] \text {, where } i \in(0,1)
$$


To define equilibrium, we find it convenient to adopt a notation that allows us to be more precise about the price and commodity space. Let $s^{t}$ denote the history of exogenous shocks up to time $t$. A sequence-of-markets equilibrium is a set of history-contingent sequences, $Z\left(s^{t}\right)$ and $Q\left(s^{t}\right)$, with the properties: (i) given the prices, the quantities solve the household and final good firm problems for each possible $s^{t}$; (ii) given the final good and factor prices, the $i^{\text {th }}$ intermediary good price, output, and inputs solve the intermediary firm's problem for each $i \in$ $(0,1)$ for each possible $s^{t}$; and (iii) the loan market-clearing condition, (13), and the resource constraints are satisfied, $C\left(s^{t}\right)=Y\left(s^{t}\right)$ and $\int_{0}^{1} K_{i}\left(s^{t}\right) d i=K\left(s^{t}\right)=1, \int_{0}^{1} N_{i}\left(s^{t}\right) d i=N\left(s^{t}\right)$, for all $s^{t}$, and all $t$. Part (iii) of our definition of equilibrium incorporates our assumption that the per capita stock of capital is unity at each date. We confine ourselves to symmetric equilibria, in which $P_{i}\left(s^{t}\right)=P\left(s^{t}\right), Y\left(s^{t}\right)=Y_{i}\left(s^{t}\right), K_{i}\left(s^{t}\right)=1$, and $N_{i}\left(s^{t}\right)=N\left(s^{t}\right)$, for all $i$. (For convenience, the timing assumptions which differentiate our two models are exhibited in Figure 9.)

To describe how we compute equilibrium, we define the state variables, $s=\left(x_{-1}, x\right)$. Under our assumptions on the money growth process, $s$ can take on nine possible values. Any set of nine $Z_{s}$ and $Q_{s}$ 's induces sequences, $\left\{Z\left(s^{t}\right), Q\left(s^{t}\right) ;\right.$ all $\left.s^{t}\right\} .{ }^{12}$ We compute $Z_{s}$ and $Q_{s}$ 's such that the implied price and quantity sequences are a competitive equilibrium. In the sticky price model, $P / M$ (the second element in $Z_{s}$ ) is restricted to vary with $x_{-1}$ only. In the limited participation model, $I / M$ is restricted to be a function of $x_{-1}$ only. The $Z_{s}$ and $Q_{s}$ 's are computed as the solution to a particular set of nonlinear equations: the first-order conditions and resource constraints for each possible $s$.

\footnotetext{
${ }^{12}$ Let $s_{t}\left(x_{t-1}, x_{t}\right)$. Here, $s^{t}=\left(s_{0}, s_{1}, \ldots, s_{t}\right)$.
} 


\section{Qualitative Properties of the Sticky Price and Limited Participation Models}

In this section, we discuss the qualitative properties of our models. We begin by comparing the nature of the output response to a money shock in the two models. We then discuss the interest rate and profit response to a monetary shock in the limited participation model. In analyzing this response, we pay particular attention to the role played by the magnitude of the labor supply elasticity and the markup.

\section{A. The Output Effects of a Money Shock in the Two Models}

We combine (13) (evaluated at equality) and (16) to obtain

$$
P_{t} C_{t}=M_{t}+X_{t}
$$

This equation must hold for interior equilibria of both versions of the model. Relation (21) defines a parabola in a graph with $P_{t}$ on the vertical axis and $C_{t}$ (or, output, $Y_{t}$, since the two are the same in our model) on the horizontal axis. This curve is depicted by the downwardsloped line labeled $D D$ in Graph 1. The curve $D D$ shifts to the right for higher values of $X_{t}$, just as the aggregate demand equation in an intermediate macroeconomics textbook does. In the sticky price model, equilibrium output, $Y$, can be thought of as the intersection of the curve $D D$ and another curve, which is horizontal at the predetermined price level. In Graph 1, this horizontal curve is labeled SS. As in the standard intermediate textbook treatment, the sticky price model depicts the economy's response to a money injection as a move along a fixed and horizontal short-run aggregate supply curve. ${ }^{13}$ So, for a money injection given by

\footnotetext{
${ }^{13}$ Below, we also consider a version of the sticky price model in which not all firms set prices in advance. In this version of the model, the short-run aggregate supply curve is, in effect, positively sloped. This change does not affect the comments we make here.
} 
$X_{t}$, equilibrium output is given by $Y$. The curve $D^{\prime} D^{\prime}$ graphs the relationship $P_{t}=\frac{M_{t}+X_{t}^{\prime}}{Y_{t}}$ for $X_{t}^{\prime}>X_{t}$. The equilibrium level of output that obtains for this larger money injection, $Y^{\prime}$, is given by the intersection of $D^{\prime} D^{\prime}$ with $S S$.

The limited participation model takes a very different position on the short-run supply curve. One way to think of this model is that its short-run supply curve, labeled $S S$ in Graph 2 , is vertical and shifts right with a money injection. A monetary injection operates in part like a technology shock: it reduces production costs by driving down the equilibrium rate of interest. The vertical curve $S^{\prime} S^{\prime}$ corresponds to the vertical supply curve that obtains for $X_{t}^{\prime}>X_{t}$. If the supply-side effect associated with the monetary shock is sufficiently large, then the equilibrium contemporaneous price response to the money injection could be zero or even negative.

To understand the supply-side effect of a monetary policy shock in the limited participation model, it is useful to understand its impact on the labor market. Relations (8) and (9) imply that in equilibrium, labor demand is given by

(22) $\frac{W_{t}}{P_{t}}=\frac{(1-\alpha) N_{t}^{-\alpha}}{\mu R_{t}}$

Relation (22) can be expressed as a labor demand schedule in real wage-employment space. This schedule is depicted by the downward-sloped line in Graph 3 labeled $D D$. Other things equal, a decrease in the interest rate shifts the labor demand curve to the right. These effects occur because the firm equates the value of labor's marginal product to a markup over the cost of hiring labor, inclusive of financing costs.

Relation (18), the household Euler equation for $N_{t}$, defines a static upward-sloped labor supply schedule. This schedule is depicted by the upward-sloped solid line in Graph 
3 labeled SS. For a given level of $R_{t}$, equilibrium employment is given by the intersection of the static labor demand and supply schedules. A lower value of the interest rate, $R^{\prime}<R$, is associated with a rightward shift in the labor demand schedule (to the curve labeled $D^{\prime} D^{\prime}$ ) and an increase in the real wage and employment. This induces a rightward shift in the aggregate supply curve in the price level/output plane.

\section{B. The Output, Interest Rate, and Profit Effects of a Monetary Policy Shock in the Limited Participation Model}

An important shortcoming of the previous intuition about the limited participation model is that it is based on an exogenous shift in the interest rate. In fact, the rate of interest is jointly determined with employment and output. To obtain intuition about the general equilibrium effects of a monetary shock, it is useful to consider a simplified version of the model in which $\phi=0$.

Taking the ratio of the labor market-clearing condition, (13), to the cash equation, (21) we obtain

$$
\frac{W_{t}}{P_{t}} \frac{N_{t}}{C_{t}}=\Gamma_{t}, \Gamma_{t}=\frac{I_{t}+X_{t}}{M_{t}+X_{t}}
$$

The variable, $\Gamma_{t}$, denotes the ratio of funds passing through the loan market to funds passing through the goods market. Since $I_{t}<M_{t}$, and these two variables are predetermined relative to $X_{t}$, a contractionary policy shock causes $\Gamma_{t}$ to fall. That is, a monetary contraction creates a relative shortage of liquidity in financial markets. This leads to a reduction in employment and output, as is explained in Christiano (1991), Christiano and Eichenbaum (1992, 1995), and Fuerst (1992). To see this, we substitute out for the real wage using the labor supply 
equation, (18), make use of $N_{t}^{1-\alpha}=C_{t}, K_{t}=1$, and rearrange, to obtain:

(24) $\quad N_{t}=\left(\frac{1}{\psi_{0}} \Gamma_{t}\right)^{\frac{1}{\psi+\alpha}}$.

Note that the size of the decrease in employment associated with a given reduction in $X_{t}$ monotonically increases in the labor supply elasticity, $1 / \psi$. With the labor supply elasticity large enough, and $\alpha$ small enough, the equilibrium response of employment to a money shock can be made arbitrarily large for given $\Gamma_{t}$. Since $P_{t}=\left(M_{t}+X_{t}\right) / N_{t}^{1-\alpha}$, this suggests there exists a value of $\psi$ for which the equilibrium price level does not respond to $X_{t}$. This reasoning abstracts from general equilibrium effects of $\psi$ on the level of $\Gamma_{t}$. But we assume these are negligible, since the nonstochastic steady-state level of $\Gamma_{t}, \Gamma$, and the value of $d \Gamma_{t} / d x_{t}$, evaluated in steady state, is invariant to $\psi$. To see this, we note that $N_{t}^{-\alpha}=C_{t} / N_{t}$ when $K_{t}=1$ and $\phi=0$, so that

$$
\Gamma_{t}=\frac{W_{t} N_{t}}{P_{t} C_{t}}=\frac{1-\alpha}{\mu R_{t}}
$$

In steady state, $R=\left(1+\mu_{x}\right) / \beta$, so that

$$
\text { (26) } \Gamma=\frac{1-\alpha}{\mu} \frac{\beta}{1+\mu_{x}}
$$

which establishes that $\Gamma$ is invariant to $\psi$. (Here, a variable without a subscript, $t$, denotes its nonstochastic steady-state value.). Next, we note that $d \Gamma_{t} / d x_{t}=\left(1-i_{t}\right) /\left(1+x_{t}\right)^{2}$, which in steady state, equals $\left[1-\left(\frac{1-\alpha}{\mu / \beta}-x\right)\right] /(1+x)^{2}$. This establishes the invariance of the steadystate value of $d \Gamma_{t} / d x_{t}$ to $\psi$.

To determine the effect of a contractionary monetary policy shock on the rate of interest, we simply rearrange (25) to get

$$
R_{t}=\frac{1-\alpha}{\mu \Gamma_{t}}
$$


Since $d \Gamma_{t} / d x_{t}>0$ for $I_{t}<M_{t},(27)$ establishes that in this version of the model, a monetary contraction must drive the equilibrium rate of interest up.

Next, we consider the impact of a monetary shock on profits. The time $t$ economic profit of intermediate good producers equals their total revenues minus total costs:

$$
P_{t} Y_{t}-R_{t} W_{t} N_{t}-r_{t} K_{t}=P_{t} Y_{t}-M C_{t}\left(Y_{t}+\phi\right)
$$

Recall from Section 2 that the measure of profits we use in our empirical analysis corresponds to accounting profits. While our empirical measure of profits nets out depreciation costs, a large portion of the return to capital (e.g., dividends) is not treated as a cost. To adjust our model-based measure of economic profits to bring it closer in line with the empirical measure of profits, we add $r_{t} K_{t}$ to economic profits. This actually overadjusts our measure of profits, because some components of rent to capital are treated as costs in our empirical measure of profits. However, one of our key conclusions is that the sticky price model counterfactually implies that profits rise after a monetary contraction. If anything, our treatment of the return to capital in profits biases our results in favor of the sticky price model. To summarize, the empirical measure of profits that we adopt is

$$
\pi_{t}=P_{t} Y_{t}-M C_{t}\left(Y_{t}+\phi\right)+r_{t}
$$

where the equilibrium condition, $K_{t}=1$, is imposed.

To determine the impact of a monetary shock on $\pi_{t}$, we note that (28) for the limited participation model reduces to

$$
\pi_{t}=\left(M_{t}+X_{t}\right)\left[1-\frac{1}{\mu}\right]+\alpha N_{t}^{1-\alpha}
$$

where the first term uses (21) and (9), and the last term corresponds to the equilibrium rent on capital. Equations (24) and (29) indicate that profits necessarily fall in response to a fall 
in $X_{t}$. Note that when $r_{t}$ is added to economic profits, it exacerbates the decline in $\pi_{t}$, after a decline in $x_{t}$.

It is of interest to understand the influence of the markup on the equilibrium effects of a monetary policy shock. From (24), it is clear that the effect on output of a monetary policy shock, $d Y_{t} / d x_{t}$, can be decomposed into two components: (i) the effect of $x_{t}$ on $\Gamma_{t}$ and (ii) the effect of $\Gamma_{t}$ on $N_{t}$. Changes in $\mu$ affect $d Y_{t} / d x_{t}$ exclusively via the first channel. From (23), we see that in our model, $\Gamma_{t}$ corresponds to the share of labor in gross output. Not surprisingly, the larger is $\mu$, the smaller is the steady-state value of $\Gamma$. (See (26).) Given $\mu_{x}$, a smaller value of $\Gamma$ corresponds to a smaller value of $I / M$, the fraction of households' beginning-of-period stock of money sent to the financial sector. The smaller is $I / M$, the larger is the impact of a given monetary injection on the pool of funds passing through the financial intermediary that are lent to firms. This implies that $d \Gamma_{t} / d x_{t}$ is larger, which in turn leads to a rise in $d N_{t} / d x_{t}$ and $d Y_{t} / d x_{t}$ (at least when evaluated in steady state). In this way, an increase in the markup raises the employment and output effects of a monetary policy shock. Note that the effect of an increase in $\mu$ on $d N_{t} / d x_{t}$ and $d Y_{t} / d x$ is similar to the effect of an increase in $1 / \psi$. However, the mechanisms by which these effects occur are different. As we note above, changes in the labor supply elasticity have a negligible impact on the magnitude of $d \Gamma_{t} / d x_{t}$ and a relatively large impact on $d N_{t} / d x_{t}$.

We conclude this section by noting that equation (29) implies that the increase in $d N_{t} / d x_{t}$ associated with a larger value of $\mu$ also implies that a given monetary shock has a larger impact on profits. In addition, it is easy to verify that $d R_{t} / d x_{t}$ is increasing (in absolute value) in $\mu$, at least when evaluated in nonstochastic steady state. As is the case regarding $d Y_{t} / d x_{t}$ and $d N_{t} / d x_{t}$, the effects of an increase in $\mu$ are similar to those of an increase in $1 / \psi$, 
but the mechanisms by which these effects occur are different.

\section{Quantitative Properties of the Sticky Price and Limited Participation Models}

Before presenting the quantitative properties of the model, we discuss how values are assigned to the parameters.

\section{A. Parameter Values}

To compute the response of the system to monetary shocks, we require values for the models' parameters. In this section, we describe the benchmark values we use in our experiments. The models' structural parameters consist of $\beta, \alpha, \psi, \mu, \phi, \psi_{0}$, and the parameters governing the evolution of $x_{t}$. We set the discount parameter $\beta$ to $(1.03)^{-.25}$. The parameter $\psi_{\mathbf{0}}$ is chosen so that, conditional on the assigned values for the other parameters, employment in nonstochastic steady state is unity.

The elasticity of labor supply with respect to the real wage rate is equal to $1 / \psi$. The value of this elasticity is controversial. Most microeconomic studies estimate it to be quite small. Typically, estimated labor supply elasticities for males are near 0. (See Card (1991), Killingsworth (1983), and Pencavel (1986).) Estimates of labor supply elasticities for females typically fall in the range 0.5-1.5. (See, for example, Killinsgworth and Heckman (1986).)

At the macroeconomic level, authors in the real business cycle literature typically work with labor supply elasticities that are much higher than those emerging from the labor literature. For example, the parameter estimates in Christiano and Eichenbaum (1992a) imply a Frisch labor supply elasticity in excess of 5.0. Authors such as Hansen (1985) assume indivisibilities in labor supply and a market structure that breaks the connection between individual 
and aggregate labor supply elasticities. Given Hansen's functional-form assumptions, the Frisch labor supply elasticity of the fictitious representative consumer whose preferences are used to compute the aggregate equilibrium is infinite. So, the range of elasticities that are used in the literature is enormous. We use a benchmark value for $\psi$ equal to 1.0 , which corresponds to a labor supply elasticity of 1.0. We demonstrate that the models' empirical performance depends sensitively on this parameter by displaying results for a range of values for $\psi$.

Next, we consider the parameters $\mu$ and $\phi$. For intermediate good firms which set their price flexibly, $\mu$ corresponds to the markup in each period. For firms which set their price prior to the realization of a money shock, $\mu$ corresponds roughly to their average markup. ${ }^{14}$ To discuss the relevant empirical range of values for $\mu$ and $\phi$, it is useful to represent the production function of a typical intermediate good firm as $Y=F(K, N)-\phi$, where $F(K, N)$ $=K^{\alpha} N^{1-\alpha}$. Profit maximization implies

(30) $\quad F_{K}=\mu \frac{r}{P}$ and $F_{N}=\mu \frac{R W}{P}$

when firms set prices flexibly. This relation only holds approximately otherwise, though for the purposes of the following discussion, we assume the relation is exact. Let $F_{J}$ denote the derivative of $F$ with respect to $J \in(K, N)$. By our linear homogeneity assumption for $F$ :

$$
\frac{F_{K} K+F_{N} N}{Y}=\frac{F}{Y}
$$

After (30) is substituted into the left side of (31), it implies that

$$
\mu\left(1-s_{\pi}\right)=\frac{F}{Y}
$$

\footnotetext{
${ }^{14}$ The correspondence is only approximate, since from (11), $E P_{i t}=\mu E \omega_{t} M C_{t}=\mu \operatorname{Cov}\left(\omega_{t}, M C_{t}\right)+\mu E M C_{t}$ $\neq \mu E M C_{t}$, unless $\operatorname{Cov}\left(\omega_{t}, M C_{t}\right)=0$.
} 
where $s_{\pi}$ is the share of economic profits, $P Y-r K-R W N$, in total nominal output. Basu and Fernald (1994), Hall (1988), and Rotemberg and Woodford (1995), among others, argue that $s_{\pi}$ is close to zero. Setting $s_{\pi}=0$, we obtain

$$
\mu=1+\frac{\phi}{Y}=\frac{1}{1-\phi}
$$

since $Y=1-\phi$, given our procedure for choosing $\psi_{0}$. Our reading of the literature is that there is very little independent evidence on $\mu$ and $\frac{\phi}{Y} \cdot{ }^{15}$ For our benchmark parameterization, we follow Hornstein (1993) in adopting the value, $\mu=1.20$. Given our diffuse priors on the size of $\frac{\phi}{Y}$, we also consider a range of other values of $\mu$. We do this both with and without imposing (33).

We now consider the parameterization of the finite-state Markov chain for $x_{t}$. We suppose $x_{t} \in\left\{\mu_{x}-\sigma, \mu_{x}, \mu_{x}+\sigma\right\}$, and let $\pi^{x}=\left\{\pi_{i j}^{x}\right\}$, where $\pi_{i j}^{x}=\operatorname{prob}\left\{x_{t+1}=x(j) \mid x_{t}=x(i)\right\}$, for $i, j=1,2,3$, and $x(j)$ corresponds to $\mu_{x}-\sigma, \mu_{x}$, and $\mu_{x}+\sigma$, respectively, for $j=1,2,3$. In our benchmark specification we set $\mu_{x}=0.02$ and $\sigma=0.017$. Also, we specify that $x_{t}$ is iid by setting each entry in $\pi^{x}$ to $1 / 3$. We also consider an alternative parameterization in which money growth is positively autocorrelated. For this, we assume the elements of $\pi^{x}$ are symmetric, so that there are five free parameters in the stochastic process for $\left\{x_{t}\right\}$ : three in $\pi^{x}$ and the two in $x(j)$, for $j=1,2,3$. We determine these by requiring that (1) the autocorrelation of $x_{t}$ be $0.5,(2)$ the standard deviation of the error in regressing $x_{t}$ on one lag of itself be $0.01,(3)\left\{x_{t}\right\}$ have the kurtosis of a normal distribution, namely, 3.0, and (4) the mean growth rate of $x_{t}$ is 0.02 . Finally, we arbitrarily set the 1,2 elements of $\pi$ to $1 / 3 .{ }^{16}$

\footnotetext{
${ }^{15}$ See Rotemberg and Woodford (1995) for a brief review of the literature.

${ }^{16}$ For further details about the procedure for parameterizing a three-state Markov chain, see Christiano
} 
Our specification of the Markov chain for $x_{t}$ implies that the growth rate of money has a first-order autoregressive representation $(A R(1))$, with an $A R$ coefficient equal to either 0.0 or 0.5 . At first glance, this parameterization might appear to be inconsistent with the empirical analysis of Section 2, where we consider monetary policy rules that are highly reactive to the state of the economy. Indeed, the view taken in both CEE and SZ is that the aim of monetary policy is to bring about a particular relationship between various endogenous variables. These relationships are given by (1) and (2), respectively. However, for either of these relationships to hold in equilibrium, the growth rate of money must respond to current and past exogenous shocks (e.g., innovations in preferences, technology, sunspots, monetary policy shocks) in an appropriate way. Under the identifying assumptions of CEE and SZ, an estimate of the way $x_{t}$ responds to current and past monetary policy shocks is given by the estimated dynamic response function of $x_{t}$ to a policy shock. Christiano, Eichenbaum and Evans (1996a) argue that when money is measured by M2, a reasonable time series representation for the response of $x_{t}$ to a policy shock is an $(\mathrm{AR}(1))$ with an $\mathrm{AR}$ coefficient equal to 0.5. (For details, see Christiano, Eichenbaum, and Evans (1996a). $)^{17}$

(1990). We use $\pi^{x}=\left(\begin{array}{lll}0.58 & 0.33 & 0.08 \\ 0.08 & 0.83 & 0.08 \\ 0.08 & 0.33 & 0.58\end{array}\right)$, and $x_{t} \in\{0.0,0.02,0.04\}$.

${ }^{17}$ The argument in Christiano, Eichenbaum and Evans (1996a) can be summarized very simply, with the aid of a money demand equation in a diagram with the nominal interest rate on the vertical axis and the money stock on the horizontal axis. Suppose, in the spirit of Section 2, that policy is represented as an interest rate target, with $\psi \equiv 0$ in (1) and two possible values for $\varepsilon_{s}: \varepsilon_{s}^{h}, \varepsilon_{s}^{l}$. Then policy can be represented by two horizontal lines, with intercepts $R^{h}=\varepsilon_{s}^{h}$ and $R^{l}=\varepsilon_{s}^{l}$. Denote the equilibrium money stocks associated with these two interest rates by $M^{h}$ and $M^{l}$. Then we have two equivalent ways to represent policy. One is already cited, namely two horizontal lines with intercepts, $\left\{R^{h}, R^{l}\right\}$. The other represents monetary policy by a money supply rule with vertical lines at $M^{h}$ and $M^{l}$. Corresponding to these two equivalent ways of representing policy, there are two methodologies for testing the model that are summarized here by the downward-sloped money demand schedule. One way is to specify policy as $\left\{R^{h}, R^{l}\right\}$ and verify that the $\left\{M^{h}, M^{l}\right\}$ predicted by the theoretical money demand curve holds in the data. This is equivalent to incorporating the interest rate rule into the model and verifying that the impulse response from monetary policy shocks to money in the model matches the one estimated from the data. Alternatively, one could specify policy as $\left\{M^{h}, M^{l}\right\}$ and verify that $\left\{R^{h}, R^{l}\right\}$ holds in the data. The methodology we adopt in this paper is in the spirit of the latter. 
We emphasize two points about our parameterization of monetary policy. First, we do not adopt the $A R(1)$ specification based on an appeal to the univariate properties of the raw M2 growth data. Such a procedure would be hard to square with our empirical analysis, according to which monetary policy is reactive to the state of the economy. Second, there is an important caveat to our analysis: when $\mathrm{M} 2$ in the $\mathrm{CEE}$ or $\mathrm{SZ}$ analysis is replaced by $\mathrm{M} 1$ or the monetary base, then the $\mathrm{AR}(1)$ representation we use to model the response of money growth to policy shocks is rejected by the data. In this case, a better approximation is a short-moving average representation in which the response of $x_{t}$ to a policy shock is initially small and then becomes larger. An important topic for further research is the extent to which the results we discuss below are robust to alternative specifications for the growth rate of money.

Finally, we turn to the parameter, $\alpha$. Estimates in Christiano (1988, footnote 3), based on the National Income and Product Accounts, suggest that the share of income going to labor, $W_{t} N_{t} /\left(P_{t} Y_{t}\right)$, averages roughly 0.64 . In the version of our model with $\phi \neq 0,(25)$ becomes

$$
\Gamma_{t}=\frac{1-\alpha}{\mu R_{t}} \frac{N_{t}^{1-\alpha}}{N_{t}^{1-\alpha}-\phi}
$$

or, after using (33) and imposing that in steady state, $N_{t}=1$, we obtain

$$
\alpha=1-R \Gamma \text {. }
$$

Given the parameter values already specified, $R=\left(1+\mu_{x}\right) / \beta=1.0276$. Given this and $\Gamma=0.64,(34)$ implies $\alpha=0.34$. In our calculations, we use $\alpha=0.36$. 


\section{B. Results}

Our results are reported in Tables 1 and 2, which display the contemporaneous equilibrium response of the system to an unanticipated fall in the growth rate of the money stock from $\mu_{x}$ to $\mu_{x}-\sigma$. In those tables, $d p$ denotes the percentage change in the price level associated with a 1 percent unanticipated change in the end-of-period stock of money. Specifically,

$$
d p=\log \left(p^{\prime} / p\right) / \log \left(\left(1+\mu_{x}\right) /\left(1+\mu_{x}-\sigma\right)\right)
$$

where $p$ denotes the price level in state $s=\left(\mu_{x}, \mu_{x}\right)$, and $p^{\prime}$ denotes the price level in state $s=\left(\mu_{x}, \mu_{x}-\sigma\right)$. The variables $d c, d n, d w, d \pi$, and $d M C$ refer to the analogous responses of consumption, employment, the real wage, profits, and marginal cost, respectively. The variable $d R$ represents the simple change in the nominal rate of interest, scaled by $\log ((1+$ $\left.\left.\mu_{x}\right) /\left(1+\mu_{x}-\sigma\right)\right)$. The variable $\chi$ in Table 1 denotes the level of the markup when money growth is $\mu_{x}-\sigma$ in the current period and when growth is $\mu_{x}$ in the previous period. Tables 1 and 2 report results for the sticky price and limited participation versions of our model, respectively.

\section{The Sticky Price Model}

The two most salient failings of the benchmark sticky price model are its counterfactual implications that profits rise and the interest rate falls in response to a monetary contraction. For example, Panel A of Table 1 indicates that for the benchmark parameter values, an unanticipated 1 percent contraction in the money stock generates a 2.95 percent rise in economic profits and a 79-basis-point fall in the interest rate. We consider each of these failings in turn and show that the model's counterfactual implication for the interest rate can 
be overturned, but its counterfactual implication for profits is more fundamental.

To understand the benchmark sticky price model's implications for the response of profits to a contractionary monetary policy shock, we recall that in equilibrium, time $t$ profits can be written as

(35) $\pi_{t}=\left(M_{t}+X_{t}\right)\left[\frac{P_{t}-M C_{t}}{P_{t}}\right]-M C_{t} \phi+r_{t}$.

Here, we make use of the fact that $P_{t} C_{t}=M_{t}+X_{t}$. In what follows it is useful to recall (8), $M C_{t}=\frac{1}{1-\alpha} N_{t}^{\alpha} W_{t} R_{t}$

As we already discussed, the price of the final good inherits the inflexibility of intermediate good prices, so that $d p=0$. Consequently, consumption and output fall by the same percentage as the money stock. Since output in the intermediate good industry is lower, aggregate employment is also lower. In the sticky price model, this corresponds to a movement along the aggregate supply curve of labor. Given our assumed labor supply elasticity, this generates a large fall in the real wage equal in magnitude to the percentage decline in employment ( 1.30 percent). With the interest rate, the real wage rate, and employment falling, marginal costs decline, and the markup rises by six percentage points, from 1.20 to 1.26 . In equilibrium, the rental rate, $r_{t}$, is given by $r_{t}=\frac{\alpha}{1-\alpha} N_{t} W_{t} R_{t}$, so it too falls. The rise in the markup overwhelms the fall in $r_{t}$ and output. The result is that profits rise after a monetary contraction.

The previous discussion suggests a variety of perturbations to assess the robustness of this result. The perturbations which we consider are motivated by a desire to identify versions of the model in which marginal costs fall by less after a monetary contraction. The first set of changes we consider are variations in the elasticity of labor supply. Panel B of 
Table 1 reveals that increasing the elasticity of labor supply does reduce the fall in wages and mitigates the rise in profits. However, even if we increase the elasticity to the incredible value of 10.0 , we still do not overturn the basic result that profits rise after a contractionary monetary shock. In Table 1, Panels C and D and row 2 of Panel E document that the profit result is robust to variations in $\mu$ and $\phi$. Panel C varies $\mu$ while changing $\phi$ according to (33) and holding all other parameter values at their benchmark values. Panel $\mathrm{D}$ varies $\mu$, holding all other parameters (including $\phi$ ) fixed at their benchmark values. Row 2 of Panel $\mathrm{E}$ sets $\phi=0$, holding all other parameter values to their benchmark values.

The next perturbation we consider is an increase in the power on labor in the production function. With a reduction in curvature on labor in the production function, a 1 percent fall in consumption requires a smaller decline in $N_{t}$. For a given elasticity of labor supply, this means that the real wage falls less in response to the contractionary money shock. Other things the same, this reduces the downward pressure on the markup and marginal costs and the upward pressure on profits. There is, however, a key countervailing force. As $\alpha$ goes to zero, the capital costs drop from profits. The first row of Panel E of Table 1 reveals that the latter effect dominates by a large margin. Now, with $\alpha=0$, profits almost triple after a contractionary monetary policy shock.

Next, we consider the effect of reducing the percentage of firms that set prices in advance. First, we consider the case in which 80 percent of the firms set prices according to (11), and 20 percent set prices flexibly, according to (9). When a subset of firms set prices flexibly, output and employment ought to fall by less in response to an unanticipated monetary contraction. This should reduce the downward pressure on marginal costs and thereby lessen the upward pressure on profits. The first row of Panel $F$ reports results for this case 
and verifies the previous conjectures: the rise in profits is now less than the rise for the benchmark model. However, the impact on the magnitude of the rise in profits is small. Further reductions in the number of price setters are likely to produce additional improvements in the model's predictions for the response of profits. However, these improvements come at a severe cost: a given reduction in the fraction of price setters produces a disproportionately large fall in the price level and a disproportionate dampening in the response of output to a contractionary monetary policy shock. This reflects the absence of strategic complementarity in price setting in our model. With a 1 percent money contraction, a given flexible price setter drops its price by more, the larger is the fraction of firms fixing prices. This happens because the larger is the fraction of firms fixing prices, the greater is their reduction in output with a given money contraction and, therefore, the greater is the general equilibrium reduction in marginal costs when they employ fewer factors of production. This accounts for the greater reduction in price by the flexible price firms, who simply set price as a given markup over marginal costs. A further discussion of what happens in our model economy when there is a mixture of flexible and fixed price firms appears below. The second row of Panel F reports results for the case in which 20 percent of the firms set price in advance. Consistent with the discussion above, this economy looks very much like a standard cash-in-advance economy. Profits do fall after a contraction, but now $d p=-0.91$ and $d c=-0.09$.

All versions of the sticky price model that we have considered so far imply that the interest rate falls with a monetary contraction. There are two reasons to consider perturbations of the model in which the interest rate rises after a monetary contraction. First, this finding is consistent with the data. Second, the interest rate decline is partially responsible for the fall in marginal costs and the rise in profits that occur in the benchmark model after 
a contractionary monetary policy shock.

We can reverse the implications of the benchmark model for the interest rate with the following utility function:

$$
U(C, N)=\frac{C^{1-\gamma}}{1-\gamma}-\psi_{0} \frac{N^{(1+\psi)}}{1+\psi}
$$

To see this, we note that the household's Euler equation, (19), and $P_{t} C_{t}=M_{t}+X_{t}$ imply

$$
C_{t} U_{c, t}=\beta R_{t} A, \text { where } A=E_{t} \frac{C_{t+1} U_{c, t+1}}{M_{t+2} / M_{t+1}}
$$

The fact that $A$ is constant reflects the benchmark model's iid assumption on the growth rate of money. Relations (36) and (37) imply

$$
R_{t}=\frac{C_{t}^{1-\gamma}}{\beta A}=\frac{\left[M_{t}+X_{t}\right]^{1-\gamma}}{\beta A P_{t}^{1-\gamma}}
$$

Since $P_{t}$ and $M_{t}$ are predetermined relative to $X_{t}$, it follows that an. increase in $X_{t}$ drives $R_{t}$ down for $\gamma>1$ and has no impact on $R_{t}$ for $\gamma=1$.

Rows 3-5 of Panel E of Table 1 report the results we obtain when adopting specification (36) of the utility function for the basic sticky price model. Row 3 reports results for the case $\gamma=\psi=1$. As expected, the interest rate is unaffected by a contractionary monetary policy shock. The basic result that profits rise after a monetary contraction is unaffected. Indeed, the rise in profits is even larger than in the benchmark model.

The basic intuition for this result is as follows. With the new utility function, the household's Euler equation for labor is given by

$$
\frac{W_{t}}{P_{t}}=\psi_{0} C_{t}^{\gamma} N_{t}^{\psi}
$$

This resembles the labor supply equation in the benchmark model, (18), with one important difference: a decrease in consumption shifts the labor supply curve to the right. It is 
still the case that a 1 percent decrease in the money supply produces a 1 percent drop in consumption. Since the production technologies in the two specifications are identical, the drop in employment must be the same. But with the new labor supply curve, the drop in consumption leads to a larger fall in the real wage rate and marginal cost. This explains why the markup and profits rise by even more than in the benchmark specification. (See row 1 of Panel A of Table 1.)

Row 4 of Panel E presents results for the same specification as row 3, except that $\gamma=2$. Now the interest rate actually rises in response to the monetary contraction. However, this effect is offset by a greater fall in the wage rate. The consequence is that profits continue to rise. Row 5 allows for a money growth rate process where the Wold representation is a firstorder autoregression with a lag coefficient equal to 0.5 and an innovation standard deviation of 0.01 . Despite the anticipated inflation effects that now come into play, the interest rate continues to rise. The counterfactual implications for profits are not affected.

To summarize our results, we find that the sticky price model fails on two key dimensions of the data. First, it implies that profits rise after an unanticipated monetary contraction. Second, and closely related, for plausible labor supply elasticities, it implies large declines in the wage rate following a contractionary monetary policy shock. An additional source of concern about the sticky price model is that the benchmark version implies that interest rates fall after a contractionary monetary policy shock. We did identify a perturbation to the model that remedies this shortcoming. However, it exacerbates the other two empirical shortcomings of the model. 


\section{The Limited Participation Model}

In this section, we consider the ability of the limited participation version of the model to account, at least in a stylized way, for the empirical regularities we document above. We show that this version of the model does at least as well, if not better than the sticky price model. Specifically, it has no difficulty generating a rise in the interest rate and a fall in profits after a contractionary monetary policy shock. Moreover, it is capable of producing small price and large output responses, but its ability to do so depends on the assumed labor supply elasticities and markups.

Our quantitative results for the benchmark specification are reported in the first row of Panel $A$ of Table 2. The key features are as follows. In contrast to the benchmark sticky price model, the interest rate rises, and profits fall, in response to a 1 percent permanent reduction in the money stock. The key failing of the benchmark model is that the primary impact of the policy shock is on prices and not on output. Specifically, prices fall by 0.62 percent, and output falls by 0.38 percent.

We now consider a series of perturbations motivated by the desire to increase the output response and decrease the price response of the system to a monetary policy shock. Panel B of Table 2 reports the results of varying the elasticity of labor supply. As expected, based on the reasoning that leads to equation (24), perturbations which increase the value of $1 / \psi$ work in the right direction. Indeed, at a labor supply elasticity of 5.0 , the output response is so large ( -1.1 percent) that prices actually rise in response to an unanticipated contractionary monetary policy shock. For all labor supply elasticities reported, the interest rate rises and profits fall in response to the shock.

Panel $\mathrm{C}$ of Table 2 reports the results of varying the markup. As in Panel $\mathrm{C}$ of Table 
1 , we simultaneously change $\phi$ so that there are no economic profits in steady state. Two key features of the results are worth noting. First, increases in the markup move the model in the desired direction. Specifically, the sensitivity of the price level to the policy shock declines, while the sensitivity of output rises. Second, if we set the markup to 1.4, the value Rotemberg and Woodford (1995) assume, we can lower the labor supply elasticity to 2.0 and obtain the result that the price level moves very little in response to a contractionary monetary policy shock ( $d p=-0.08$ percent, and $d c=-0.92$ percent). While this labor supply elasticity is high relative to some micro-based estimates, it is small relative to the range considered in the real business cycle literature.

Panel $\mathrm{D}$ reports the results of varying the markup, holding $\phi$ constant at its benchmark value. Consistent with the discussion in Section 4.B, an increase in $\mu$ (i) increases the extent of the fall in employment, consumption and the real wage, (ii) increases the rise in the interest rate, and (iii) mutes the fall in the price level. Comparing Panels $\mathrm{C}$ and $\mathrm{D}$, we see that decreases in $\phi$, per se, have the same qualitative effect on the response of the system to a contractionary policy shock as an increase in $\mu$. A different way to see this is to compare the results for the benchmark parameter values of row 1 of Panel $A$ with the results in row 2 of Panel E, which are obtained with the benchmark parameter values except that $\phi$ is set to zero.

For completeness, Panel $\mathrm{E}$ of Table 2 reports the results of the experiments analogous to those analyzed in Panel $\mathrm{E}$ of Table 1. The two main findings are as follows. First, when we increase the share of labor, this leads to a deterioration of the benchmark model's performance. Specifically, prices respond by more to a contractionary monetary policy shock. Moreover, profits actually rise. Second, the effect of moving to the alternative functional form 
for utility has relatively little impact on the model's performance. Relative to the benchmark model, the output effect is somewhat weaker, and the price effect is somewhat stronger. This is consistent with the intuition we offer above, according to which the change in functional form has effects similar to a reduction in the labor supply elasticity.

One obvious perturbation of the limited participation model is to assume that a subset of the intermediate good firms set their price in advance of the realization of $x_{t}$, thus magnifying the effect of a policy shock on aggregate output. Panel F considers the consequences when we assume that 80 percent of the intermediate good firms set prices in advance. The first row reports the impact of the change on our benchmark specification. Interestingly, the impact is quite small. With the change, the price and output responses are -0.48 and -0.52 percent, respectively. These are to be compared with the -0.62 and -0.38 figures from Panel A. The reason that adding price setters does little to reduce the price effect of a money shock is very similar to the reasoning we use to explain the consequences of reducing the percentage of price setters in the sticky price model from 100 percent to 80 percent. (See Panel F of Table 1.) For the 80 percent of firms who set prices in advance in the limited participation model, the output effect of a money contraction is greater than in the equilibrium when each firm sets prices flexibly. In particular, their output falls by a full 3.39 percent, and their employment falls by 3.0 percent. The key to understanding the relatively small effect of a money contraction on aggregate output and the relatively large effect on the price level is to consider the price and output response of the other 20 percent of intermediate good producers who set prices flexibly. The large drop in employment by the fixed price firms leads to a large drop in the marginal cost of production. According to Panel A, the marginal cost of production falls by 0.62 percent when all prices are set flexibly. In contrast, marginal costs fall by 2.06 
percent when 80 percent of firms fix prices in advance. This drop in marginal costs leads the flexible price firms to drop their prices by 2.06 percent and to actually increase output and employment by 8.96 percent and 7.46 percent, respectively. In effect, it is the complete absence of strategic complementarity in price setting that accounts for the small impact of price setting in the model: Alexible price setters are encouraged to reduce prices by more, the larger is the fraction of firms which fix prices in advance. For completeness, row 2 of Panel F reports results for the case in which 20 percent of the firms set price in advance. Consistent with the discussion above, the results are extremely similar to those which we obtain when none of the firms set price in advance. (See row 1 of Panel A of Table 2.)

The previous reasoning suggests that introducing sticky price firms into the limited participation model would have a greater impact on reducing the price effect of a money shock, if we incorporate limitations on the intersectoral mobility of factors of production. To investigate this possibility we modify the version of the limited participation model in which the fraction $(1-v)$ of the intermediate good firms set prices in advance as follows. We denote the sector of the economy in which intermediate good firms set prices flexibly and the sector in which they set prices in advance as sector 1 and 2 , respectively. We assume that fraction $v$ and $(1-v)$ of the population work in sectors 1 and 2 , respectively. The assumption that $v$ is not a state-dependent choice of the household captures limited intersectoral immobility of labor. We modify the preferences of the representative household as follows:

$$
U\left(C, N_{1}, N_{2}\right)=\log \left\{C-v \frac{\psi_{0}}{1+\psi} N_{1}^{1+\psi}-(1-v) \frac{\psi_{0}}{1+\psi} N_{2}^{1+\psi}\right\}
$$

where $N_{i}$ denotes hours of work in sectors $i=1,2$, respectively. The time $t$ wage rate in sector $i$ is given by $W_{i t}$, where $i=1,2$. The cash constraint on the household's consumption 
purchases, (16), is replaced by the constraint

$$
P_{t} C_{t} \leq v W_{1 t} N_{1 t}+(1-v) W_{2 t} N_{2 t}+M_{t}-I_{t}
$$

The household is endowed with one unit of capital, which it allocates to capital markets in the two sectors of the economy subject to the constraint

(40) $v K_{1 t}+(1-v) K_{2 t}=1$

Here, $K_{i t}$ denotes the amount of capital supplied to sector $i=1,2$. The time $t$ rental rate on capital in sector $i$ is given by $r_{i t}$, where $i=1,2$. The household chooses $K_{i t}$ before the time $t$ realization of $X_{t}$. This assumption captures limited intersectoral mobility of capital.

We replace (17), which governs the evolution of the household's money holdings, with

$$
\begin{aligned}
M_{t+1}= & {\left[v W_{1 t} N_{1 t}+(1-v) W_{2 t} N_{2 t}+M_{t}-I_{t}-P_{t} C_{t}\right] } \\
& +r_{1 t} v K_{1 t}+(1-v) r_{2 t} K_{2 t}+R_{t}\left[I_{t}+X_{t}\right]+D_{1 t}+D_{2 t} .
\end{aligned}
$$

Here, $D_{1 t}$ and $D_{2 t}$ denote time $t$ profits from intermediate good producers in the two sectors. The household maximizes (38), subject to (39) - (41). It chooses $C_{t}, N_{1 t}, N_{2 t}$, and $M_{t+1}$ after the realization of $X_{t}$. It chooses $I_{t}, K_{1 t}$, and $K_{2 t}$ before the realization of $X_{t}$.

The first-order necessary conditions associated with the household's choice of $N_{i t}$ are given by

(42) $\frac{W_{i t}}{P_{t}}=\psi_{0} N_{i t}^{\psi}$

where $i=1,2$. The Euler equation for $I_{t}$ is still given by (20). The household's Euler equations for $K_{1 t}$ and $K_{2 t}$ imply that

$$
E_{t-1} \frac{U_{c, t+1}}{P_{t+1}}\left(r_{1 t}-r_{2 t}\right)=0 .
$$


The problem of the final good firm is unaffected, so that the demand equation for intermediate good $i$ is still given by (4). The problems of the intermediate good firms in the two sectors are the same as we describe in Section 3 of the paper. As before, we confine ourselves to symmetric equilibria. Let $K_{i t}$ and $N_{i t}$ denote the amount of capital and labor hired by the typical firm in sector $i=1,2$. Firms' Euler equations for $K_{i t}$ and $N_{i t}$ imply

(44) $\frac{r_{i t}}{W_{i t} R_{t}}=\frac{\alpha}{1-\alpha} \frac{N_{i t}}{K_{i t}}$

where $i=1,2$. The typical firm in the flexible price sector continues to set its price as a constant markup over marginal cost, according to (9). The typical firm in the inflexible price sector continues to set its price as a constant markup over a weighted expectation of marginal cost, according to (11) and (12). Marginal cost for the two types of firms is given by

$$
M C_{i t}=A\left(\frac{r_{i t}}{W_{i t} R_{t}}\right)^{\alpha} W_{i t} R_{t}
$$

where $i=1,2$, and where $A$ is defined immediately after (7). Economywide output is given by

$$
Y_{t}=\left[v\left(\left(\frac{K_{1 t}}{N_{1 t}}\right)^{\alpha} N_{1 t}-\phi\right)^{\frac{1}{\mu}}+(1-v)\left(\left(\frac{K_{2 t}}{N_{2 t}}\right)^{\alpha} N_{2 t}-\phi\right)^{\frac{1}{\mu}}\right]^{\mu}
$$

and the economywide price level is given by

$$
P_{t}=\left[v P_{1 t}^{\frac{1}{1-\mu}}+(1-v) P_{2 t}^{\frac{1}{1-\mu}}\right]^{1-\mu}
$$

The loan market-clearing condition (13) is replaced by

$$
v W_{1 t} N_{1 t}+(1-v) W_{2 t} N_{2 t}=I_{t}+X_{t}
$$

Finally, the definition of an equilibrium is the same as that given in Section 3, except that $W_{t}$ and $r_{t}$ are replaced by $\left(W_{1 t}, W_{2 t}\right)$ and $\left(r_{1 t}, r_{2 t}\right)$, respectively. We compute an equilibrium by solving a suitably modified version of the nonlinear equations discussed in Section 3 . 
Panel G of Table 2 reports the response of the previous model economy to a monetary policy shock that assumes our benchmark parameter values and that 20 percent of the firms set prices in advance (e.g., $v=0.8$ ). Comparing these results to row 2 of Panel F of Table 2, we see that introducing limited intersectoral mobility does reduce the magnitude of $d p$ and does increase the magnitude of $d c$ and $d n$. However, these effects are small and come at a large cost: the interest rate falls, and profits rise after a contractionary shock. ${ }^{18}$

The introduction of limitations on intersectoral mobility of production factors evidently helps very little. To gain intuition into this result, we recall that fixed price firms substantially reduce their use of productive resources when there is a monetary contraction. Absent limitations on intersectoral mobility, this results in a large flow of resources from the fixed price sector to the flexible price sector. The resulting downward pressure on factor costs encourages flexible price firms to cut prices and expand output. Limitations on the intersectoral mobility of factors moderate this phenomenon: labor and capital released from the fixed price sector cannot find their way to the flexible price sector in the period of a monetary shock. As a result, the contraction of the fixed price sector does not release capital and labor for use in the flexible price sector. However, the limited intersectoral mobility assumption does not restrict the intersectoral flow of cash. The contraction of the fixed price sector results in a drop in the demand for money by firms in that sector. This demand by firms appears to reduce the equilibrium interest rate, which drives down marginal costs of flexible price firms and encourages them to cut prices and increase output.

We now summarize our results for the limited participation model. Our major finding

\footnotetext{
${ }^{18}$ For the purpose of these calculations, $N_{t}=v N_{1 t}+(1-v) N_{2 t}$ and $W_{t}=\left(v W_{1 t} N_{1 t}+(1-v) W_{2 t} N_{2 t}\right) / N_{t}$. Also, $d M C_{1 t}=-5.73$ and $d M C_{2 t}=-7.56$.
} 
is as follows. If one is willing to assume a high labor supply elasticity (e.g., 2 percent) and a reasonably high markup (e.g., 40 percent), then the limited participation model can account in a stylized way for the facts we stress in this section. Specifically, an iid shock to the growth rate of money has essentially no contemporaneous impact on the price level and drives wages, profits, output, and employment down, while driving the rate of interest up. If one is not willing to accept high markups and labor supply elasticities, then the model has difficulty generating a large output effect and a small price effect from a monetary policy shock. From this perspective, a fruitful avenue for future research would be to investigate labor market frictions which raise the effective elasticity of labor supply.

\section{Conclusion}

In this paper, we assessed the ability of two classes of models to account for the salient facts about how the economy responds to an unanticipated monetary policy shock. Each class of models stresses a particular type of friction that generates monetary nonneutrality. The first friction is sticky good prices. The second is a friction in financial markets. Both models suffer from related shortcomings. In our view, a model that convincingly accounts for the key effects of a monetary policy shock will have to allow for labor market frictions which increase the effective elasticity of labor supply, in addition to one of the two frictions we consider in this paper.

The key problem with the sticky price model is that it cannot account for the fact that profits fall after a contractionary monetary policy shock. Indeed, the model has the perverse implication that profits actually rise after such a shock. This happens because, absent labor market frictions or an implausibly high labor supply elasticity, marginal costs 
fall and markups rise sharply after a contractionary monetary policy shock. The presence of wage contracts is one obvious friction which would help overturn the model's counterfactual implications. If these wage contracts had the property that employment falls after a contractionary policy shock but the wage does not, then marginal costs would not drop by as much after a contractionary monetary policy shock, and profits might not rise. Allowing for endogenous capacity utilization might also render the sticky price model consistent with the key facts. As Burnside and Eichenbaum (1996) stress, with endogenous capacity utilization, the supply of capital services to the economy is no longer predetermined in any given period. Consequently, employment and marginal costs would not fall so much in response to a contractionary policy shock. This could overturn the sticky price model's counterfactual implications for profits.

The key problem with the limited participation model is that it cannot account for the fact that prices do not immediately respond to a monetary shock, at least not with a plausible labor supply elasticity. Allowing for wage contracts which effectively increased the response of employment to monetary shocks, would clearly improve the model's performance. So too would endogenous capacity utilization that magnifies the response of output to shocks. An important additional advantage of allowing for endogenous capacity utilization is that it could render both the sticky price and limited participation models consistent with the fact that labor productivity is procyclical. 


\section{References}

Basu, S. 1995. Intermediate goods and business cycles: Implications for productivity and welfare. American Economic Review 85: 512-31.

Basu, S., and Fernald, J. 1994. Constant returns and small markups in U.S. manufacturing. Working paper. International Finance Discussion Paper No. 483. Board of Governors of the Federal Reserve System.

Benhabib, J.; Rogerson, R.; and Wright, R. 1991. Homework in macroeconomics: Household production and aggregate fluctuations. Journal of Political Economy 99 (6): 1166-87.

Blanchard, O.J., and Kiyotaki, N. 1987. Monopolistic competition and the effects of aggregate demand. American Economic Review 77 (4): 647-66.

Burnside, C., and Eichenbaum, M. 1996. Factor hoarding and the propagation of business cycle shocks. Forthcoming American Economic Review.

Card, D. 1991. Intertemporal labor supply: An assessment. National Bureau of Economic Research Working Paper No. 3602.

Chari, V.V.; Christiano, L.; and Eichenbaum, M. 1995. Inside money, outside money, and short-term interest rates. Journal of Money, Credit, and Banking 27 (4) (November, Part 2): 1354-86.

Chari, V.V.; Kehoe P.; and McGrattan, E. 1996. Sticky price models of the business cycle: The persistence problem. Manuscript. University of Minnesota.

Cho, J.O., and Cooley, T. 1995. The business cycle with nominal contracts. Economic Theory 6 (1): 13-33.

Christiano, L.J. 1988. Why does inventory investment fluctuate so much? Journal of Mon- 
etary Economics 21 (2/3): 247-80.

. 1990. Linear-quadratic approximation and value-function iteration: A comparison. Journal of Business and Economic Statistics 8 (1): 99-113.

1991. Modeling the liquidity effect of a money shock. Federal Reserve Bank of Minneapolis Quarterly Review 15 (Winter): 3-34.

Christiano, L.J., and Eichenbaum, M. 1992. Liquidity effects and the monetary transmission mechanism. American Economic Review 82 (2): 346-53.

. 1992a. Current real-business cycle theories and aggregate labor-market fluctu-

ations. American Economic Review 82 (3): 430-50.

. 1994. Interest rate smoothing in an equilibrium business cycle model. Manuscript. Northwestern University.

- 1995. Liquidity effects, monetary policy, and the business cycle. Journal of Money, Credit, and Banking 27 (4) (November, Part 1): 1113-36.

Christiano, L.J.; Eichenbaum, M.; and Evans, C. 1996. The effects of monetary policy shocks: Some evidence from the flow of funds. Review of Economics and Statistics, 78 (1): $16-34$.

. 1996a. Modeling money. Manuscript. Northwestern University.

Fuerst, T.S. 1992. Liquidity, loanable funds, and real activity. Journal of Monetary Economics 29 (1): $3-24$.

Hall, R. 1988. The relation between price and marginal cost in U.S. industry. Journal of Political Economy 96 (5): 921-47.

Hansen, G. 1985. Indivisible labor and the business cycle. Journal of Monetary Economics $16(3): 309-27$. 
Hornstein, A. 1993. Monopolistic competition, increasing to scale, and the importance of productivity shocks. Journal of Monetary Economics 31 (3): 299-316.

Ireland, P. 1995. Sustainable monetary policies. Manuscript. Federal Reserve Bank of Richmond.

Killingsworth, M. 1983. Labor Supply. New York: Cambridge University Press.

Killingsworth, M., and Heckman, J. 1986. Female labor supply: A survey. In Handbook of Labor Economics, ed. O. Ashenfelter and R. Layard, Handbooks in Economics Series, no. 5, Vol. 1, pp. 103-204. North-Holland: Elsevier Science.

King, R., and Watson, M. 1996. Money, prices, interest rates and the business cycle. Review of Economics and Statistics 78 (1): 35-53.

Lucas, R.E., Jr. 1972. Expectations and the neutrality of money. Journal of Economic Theory 4 (2): 103-24. 1990. Liquidity and interest rates. Journal of Economic Theory 50 (2): 237-64.

Ohanian, L.H.; Stockman, A.; and Kilian, L. 1995. The effects of real and monetary shocks in a business cycle model with some sticky prices. Journal of Money, Credit, and Banking 27 (4) (November, Part 2), 1209-34.

Pencavel, J. 1986. Labor supply of men: A survey. In Handbook of Labor Economics, ed. O. Ashenfelter and R. Layard, Handbooks in Economics Series, no. 5, Vol. 1, pp. 3-102. North-Holland: Elsevier Science.

Romer, D. 1996. Advanced Macroeconomics. New York: McGraw Hill.

Rotemberg, J., and Woodford, M. 1995. Dynamic general equilibrium models with imperfectly competitive product markets. In Frontiers of Business Cycle Research, ed. Thomas F. Cooley, pp. xvi and 419. Princeton: Princeton University Press. 
Sims, C., and Zha, T. 1995. Does monetary policy generate recessions? Manuscript. Yale University. . 1995a. Error bands for impulse responses. Working Paper 95-6. Federal Reserve Bank of Atlanta.

U.S. Department of Commerce. Bureau of Economic Analysis. 1985. Corporate profits: Profits before tax, profits tax liability, and dividends. Methodology Paper Series MP-2. Washington, D.C.: GPO.

Woodford, M. 1996. Control of the public debt: A requirement for price stability. Manuscript. Princeton University. 


\section{Appendix A}

We use the following time series to estimate the CEE policy shock measures.

Logged GDP in fixed-weight 1987 dollars, seasonally adjusted (SA); logged GDP deflator derived from nominal GDP and GDP in fixed-weight 1987 dollars, SA; change in index of sensitive materials prices, including commodity prices, smoothed; federal funds rate; logged nonborrowed reserves, $\mathrm{SA}$; logged total reserves, $\mathrm{SA}$; and the change in the log of $\mathrm{M} 2, \mathrm{SA}$. These data series are taken from the Federal Reserve Board's macroeconomic database.

The following time series are used to estimate the SZ policy shock measures.

Logged producer price index crude materials, SA; logged producer price index intermediate materials, SA; logged GDP in fixed-weight 1987 dollars, SA; logged GDP deflator derived from nominal GDP and GDP in fixed-weight 1987 dollars, SA; three-month Treasury bill rate; and change in the log of M2, SA. These data series are taken from the Federal Reserve Board's macroeconomic database. Logged average hourly earnings of private nonagricultural production workers are divided by the GDP deflator, SA, and are derived from the Citibase data set.

The following measures of real wages are used in our estimation exercises.

Average hourly earnings (AHE) of private nonagricultural production workers (from 1964:Q1 to 1995:2); AHE of private nonagricultural production workers, are deflated by the Bureau of Labor Statistics using a derivation of the Consumer Price Index for Urban Wage Earners and Clerical Workers (from 1964:Q1 to 1992:3); AHE of manufacturing sector; AHE of manufacturing durable goods sector; AHE of manufacturing nondurable goods sector; AHE of food and kindred product sector; AHE of tobacco manufacturing sector; AHE of 
textile mill products sector; AHE of apparel and other textile products sector; AHE of paper and allied products sector; AHE of printing and publishing sector; AHE of chemicals and allied products sector; AHE of petroleum and coal products sector; AHE of rubber and miscellaneous plastics products sector; AHE of leather and leather products sector; AHE of lumber and wood products sector; AHE of furniture and fixtures sector; AHE of stone, clay, and glass products sector; AHE of primary metal industries sector; AHE of fabricated metal products sector; AHE of machinery sector-except electrical; AHE of electric and electronic equipment sector; AHE of transportation equipment sector; AHE of instruments and related products sector; and AHE of miscellaneous of durable manufacturing goods sector. All wages are taken from the Citibase data set and are seasonally adjusted. All wage data are divided by the GDP deflator and are logged, except where noted.

The profit data we use in our analysis are accounting profits, namely income earned in current production. (See U.S. Department of Commerce (1985).) The following measures of corporate profits are used in our empirical exercises.

Profits before tax with inventory valuation and capital consumption adjustment, SA; Profits after tax with inventory valuation and capital consumption adjustment, SA; Net domestic profits after tax with inventory valuation and capital consumption adjustment, SA; Nonfinancial net domestic profits after tax with inventory valuation and capital consumption adjustment, SA; Profits after tax excluding net interest costs, SA; Net domestic profits after tax excluding net interest costs, SA; Nonfinancial net domestic profits after tax excluding net interest costs, SA; Domestic manufacturing profits before tax with inventory valuation adjustment, SA; Domestic durable goods manufacturing profits before tax with inventory valuation adjustment, SA; Domestic nondurable goods manufacturing profits before tax with 
inventory valuation adjustment, SA; Domestic transportation and public utilities profits before tax with inventory valuation adjustment, SA; Domestic retail trade profits before tax with inventory valuation adjustment, SA. All profit series data taken from the Federal Reserve Board's macroeconomic database.

As explained in U.S. Department of Commerce (1985) for corporate profits with inventory valuation adjustment and capital consumption adjustment, profits are measured as receipts less expenses as defined in federal tax law. However, receipts exclude capital gains and dividends received, expenses exclude depletion and capital losses, inventory withdrawals are valued at current replacement cost, and depreciation is on a consistent accounting basis and valued at current replacement cost. 


\section{Appendix B}

In this appendix, we describe the identification scheme underlying our version of the SZ policy shock measure. Suppose that the economy is described by a structural model of the form

$$
B_{0} Z_{t}=B_{1} Z_{t-1}+\ldots .+B_{q} Z_{t-q}+\varepsilon_{t}
$$

Here, $Z_{t}$ denotes an $l$ dimensional vector of observable variables, $B_{i}$ is an $l$ by $l$ dimensional matrix, $i \in[1, \ldots, q]$, the diagonal elements of $B_{0}$ are unity, $B_{0}$ is assumed to be invertible, and $\varepsilon_{t}$ is an $l$ dimensional vector of structural disturbances to the economy. The vector $\varepsilon_{t}$ is assumed to be uncorrelated with $Z_{t-j}$, for all $j>0$, and the covariance matrix of $\varepsilon_{t}$,

(50) $E \varepsilon_{t} \varepsilon_{t}^{\prime}=\Lambda$

is diagonal. The diagonal elements of $\Lambda$ are the variances of the structural shocks to the economy. Relation (49) implies the following reduced-form VAR for $Z_{t}$ :

$$
Z_{t}=A_{1} Z_{t-1}+\ldots+A_{q} Z_{t-q}+u_{t}
$$

The covariance matrix, $\Sigma$, of $u_{t}$ is

$$
\Sigma=\left(B_{0}^{-1}\right) \Lambda\left(B_{0}^{-1}\right)^{\prime}
$$

The $A_{i}$ 's are given by

$$
A_{i}=B_{0}^{-1} B_{i}
$$

The disturbance term $u_{t}$ is related to $\varepsilon_{t}$ via the relationship

$$
u_{t}=B_{0}^{-1} \varepsilon_{t}
$$


The vector $Z_{t}$ includes the $\log$ of crude materials prices $(P \mathrm{~cm})$, the first difference of the log of M2 (M2), the three-month Treasury bill rate (Tbill), the log of intermediate materials prices $($ Pim), the log of the implicit GDP deflator $(P)$, the log of real wages $(W / P)$, and the $\log$ of real GDP $(Y)$. Sims and Zha (1995) achieve identification by the following specification of the $B_{0}$ matrix:

$$
\left[\begin{array}{c}
\varepsilon_{P c m} \\
\varepsilon_{M D} \\
\varepsilon_{M P} \\
\varepsilon_{P i m} \\
\varepsilon_{P} \\
\varepsilon_{w / p} \\
\varepsilon_{y}
\end{array}\right]=\left[\begin{array}{ccccccc}
B_{11} & B_{12} & B_{13} & B_{14} & B_{15} & B_{16} & B_{17} \\
0 & B_{22} & B_{23} & 0 & B_{25} & 0 & B_{27} \\
B_{31} & B_{32} & B_{33} & 0 & 0 & 0 & 0 \\
B_{41} & 0 & 0 & B_{44} & B_{45} & B_{46} & B_{47} \\
B_{51} & 0 & 0 & 0 & B_{55} & B_{56} & B_{57} \\
B_{61} & 0 & 0 & 0 & 0 & B_{66} & B_{67} \\
B_{71} & 0 & 0 & 0 & 0 & 0 & B_{77}
\end{array}\right]\left[\begin{array}{c}
u_{P c m} \\
u_{M 2} \\
u_{T b i l l} \\
u_{P i m} \\
\cdot \\
u_{P} \\
u_{w / p} \\
u_{y}
\end{array}\right]
$$

along with the overidentifying restriction that $B_{25}=B_{27}=-B_{22}$. We refer the reader to Sims and Zha (1995) for a discussion of this identification scheme. In our version of SZ, we do not impose restrictions on $B_{25}$ and $B_{27}$.

For our analysis of profits, we augment the vector $Z_{t}$ to include the ratio of profits to GDP (Prof). Identification in the 8-variable system is achieved by adding an eighth row and column to $B_{0}$ in (55) for $\varepsilon_{\text {Prof }}$ and $u_{\text {Prof }}$. The additional nonzero elements in $B_{0}$ are $B_{18}, B_{48}, B_{58}, B_{68}, B_{78}, B_{81}$, and $B_{88}$. 
Table 1

Responses to a Monetary Contraction-Fixed Price Model

\begin{tabular}{|c|c|c|c|c|c|c|c|c|}
\hline & $\overline{d p}$ & $\overline{d c}$ & $\overline{d n}$ & $d w$ & $d M C$ & $\overline{d R}$ & $\chi$ & $\overline{d \pi}$ \\
\hline & \multicolumn{8}{|c|}{ Panel A: Benchmark Parameter Values } \\
\hline & 0.00 & -1.00 & -1.30 & -1.30 & -2.54 & -0.79 & 1.26 & 2.95 \\
\hline & \multicolumn{8}{|c|}{ Panel B: Different Labor Supply Elasticities } \\
\hline $1 / \psi=0.1$ & 0.00 & -1.00 & -1.30 & -12.99 & -14.20 & -0.75 & 1.64 & 15.94 \\
\hline $1 / \psi=0.5$ & 0.00 & -1.00 & -1.30 & -2.60 & -3.85 & -.080 & 1.30 & 4.91 \\
\hline $1 / \psi=5$ & 0.00 & -1.00 & -1.30 & -0.26 & -1.44 & -0.73 & 1.24 & 1.19 \\
\hline \multirow[t]{2}{*}{$1 / \psi=10$} & 0.00 & -1.00 & -1.30 & -0.13 & -1.29 & -0.71 & 1.23 & 0.94 \\
\hline & \multicolumn{8}{|c|}{ Panel C: Different Markup Values } \\
\hline$\mu=1.01$ & 0.00 & -1.00 & -1.55 & -1.55 & -3.02 & -0.93 & 1.07 & $\overline{3.92}$ \\
\hline$\mu=1.20$ & 0.00 & -1.00 & -1.30 & -1.30 & -2.54 & -0.79 & 1.26 & 2.95 \\
\hline$\mu=1.40$ & 0.00 & -1.00 & -1.11 & -1.11 & -2.23 & -0.73 & 1.46 & 2.26 \\
\hline \multirow[t]{2}{*}{$\mu=2.00$} & 0.00 & -1.00 & -0.78 & -0.78 & -1.75 & -0.71 & 2.07 & 1.15 \\
\hline & \multicolumn{8}{|c|}{ Panel D: Different Markup Values, Benchmark $\phi$} \\
\hline$\mu=1.01$ & 0.00 & -1.00 & -1.30 & -1.30 & -2.70 & -0.95 & 1.07 & 6.25 \\
\hline$\mu=1.40$ & 0.00 & -1.00 & -1.30 & -1.30 & -2.43 & -0.68 & 1.47 & 1.61 \\
\hline \multirow[t]{2}{*}{$\mu=2.00$} & 0.00 & -1.00 & -1.30 & -1.30 & -2.25 & -0.50 & 2.09 & 0.26 \\
\hline & \multicolumn{8}{|c|}{ Panel E: Miscellaneous } \\
\hline$\alpha=0$ & 0.00 & -1.00 & -0.83 & -0.83 & -1.56 & -0.74 & 1.24 & 198.61 \\
\hline$\phi=0$ & 0.00 & -1.00 & -1.56 & -1.56 & -2.85 & -0.74 & 1.27 & 2.06 \\
\hline Modified Preferences, $\gamma=1$ & 0.00 & -1.00 & -1.30 & -2.30 & -2.77 & 0.00 & 1.27 & 3.30 \\
\hline Modified Preferences, $\gamma=2$ & 0.00 & -1.00 & -1.30 & -3.30 & -2.77 & 1.04 & 1.27 & 3.30 \\
\hline \multirow{2}{*}{$\underset{\text { (Persistent Shocks) }}{\text { Modified Preferences, } \gamma=2}$} & 0.00 & -1.00 & -1.30 & -3.30 & -2.77 & 1.04 & 1.27 & 3.30 \\
\hline & \multicolumn{8}{|c|}{ Panel F: Partial Price Setting } \\
\hline $80 \%$ Price Setters & -0.40 & -0.60 & -0.72 & -0.72 & -1.86 & -0.48 & 1.24 & 1.25 \\
\hline $20 \%$ Price Setters & -0.91 & -0.09 & -0.10 & -0.10 & -1.12 & -0.08 & 1.21 & -0.67 \\
\hline
\end{tabular}


Table 2

Responses to a Monetary Contraction - Limited Participation Model

\begin{tabular}{|c|c|c|c|c|c|c|c|}
\hline & $d p$ & $\overline{d c}$ & $\overline{d n}$ & $\overline{d w}$ & $\overline{d M C}$ & $\overline{d R}$ & $\overline{d \pi}$ \\
\hline & \multicolumn{7}{|c|}{ Panel A: Benchmark Parameter Values } \\
\hline & -0.62 & -0.38 & -0.50 & -0.50 & -0.62 & 0.70 & -1.11 \\
\hline & \multicolumn{7}{|c|}{ Panel B: Different Labor Supply Elasticities } \\
\hline $1 / \psi=0.1$ & -0.95 & -0.05 & -0.06 & -0.60 & -0.95 & 0.64 & -1.01 \\
\hline $1 / \psi=0.5$ & -0.79 & -0.21 & -0.28 & -0.55 & -0.79 & 0.67 & -1.06 \\
\hline $1 / \psi=5$ & 0.10 & -1.10 & -1.43 & -0.29 & 0.10 & 0.83 & -1.33 \\
\hline $1 / \psi=10$ & 0.43 & -1.43 & -1.86 & -0.19 & 0.43 & 0.89 & -1.43 \\
\hline \multicolumn{8}{|c|}{ Panel C: Different Markup Values } \\
\hline$\mu=1.01$ & -0.71 & -0.29 & -0.45 & -0.45 & -0.71 & 0.64 & -1.01 \\
\hline$\mu=1.20$ & -0.62 & -0.38 & -0.50 & -0.50 & -0.62 & 0.70 & -1.11 \\
\hline$\mu=1.40$ & -0.50 & -0.50 & -0.56 & -0.56 & -0.50 & 0.78 & -1.26 \\
\hline$\mu=1.40,1 / \psi=2$ & -0.08 & -0.92 & -1.02 & -0.51 & -0.08 & 0.91 & -1.47 \\
\hline$\mu=2.00$ & 0.11 & -1.11 & -0.86 & -0.86 & 0.11 & 1.22 & -2.00 \\
\hline$\mu=2.00,1 / \psi=.5$ & -0.54 & -0.46 & -0.36 & -0.72 & -0.54 & 0.87 & -1.41 \\
\hline & \multicolumn{7}{|c|}{ Panel D: Different Markup Values, Benchmark $\phi$} \\
\hline$\mu=1.01$ & -0.78 & -0.22 & -0.29 & -0.28 & -0.78 & 0.40 & -1.12 \\
\hline$\mu=1.40$ & -0.45 & -0.55 & -0.72 & -0.72 & -0.45 & 1.02 & -1.11 \\
\hline$\mu=2.00$ & 0.07 & -1.07 & -1.40 & -1.40 & 0.07 & 1.98 & -1.00 \\
\hline & \multicolumn{7}{|c|}{ Panel E: Miscellaneous } \\
\hline$\alpha=0$ & -0.96 & -0.04 & -0.03 & -0.03 & -0.96 & 0.04 & 24.44 \\
\hline$\phi=0$ & -0.56 & -0.44 & -0.69 & -0.69 & -0.56 & 0.98 & -1.00 \\
\hline Modified Preferences, $\gamma=1$ & -0.76 & -0.24 & -0.31 & -0.54 & -0.76 & 0.68 & -1.07 \\
\hline Modified Preferences, $\gamma=2$ & -0.83 & -0.17 & -0.22 & -0.56 & -0.83 & 0.66 & -1.05 \\
\hline Modified Preferences, $\gamma=2$ & -0.83 & -0.17 & -0.22 & -0.56 & -0.83 & 0.66 & -1.05 \\
\hline & \multicolumn{7}{|c|}{ Panel F: Partial Price Setting } \\
\hline $80 \%$ Price Setters & -0.48 & -0.52 & -0.57 & -0.57 & -2.06 & -0.81 & 1.35 \\
\hline $20 \%$ Price Setters & -0.61 & -0.39 & -0.50 & -0.50 & -0.75 & 0.56 & -0.87 \\
\hline & \multicolumn{7}{|c|}{ Panel G: Limited Intersectoral Mobility } \\
\hline $20 \%$ Price Setters & -0.53 & -0.47 & -0.59 & -0.50 & * & -0.64 & 0.14 \\
\hline
\end{tabular}

*Marginal cost responses are not reported because they differ across the fixed and flexible price firms. 
Graph 1

Equilibrium Price and Output in the Sticky Price Model

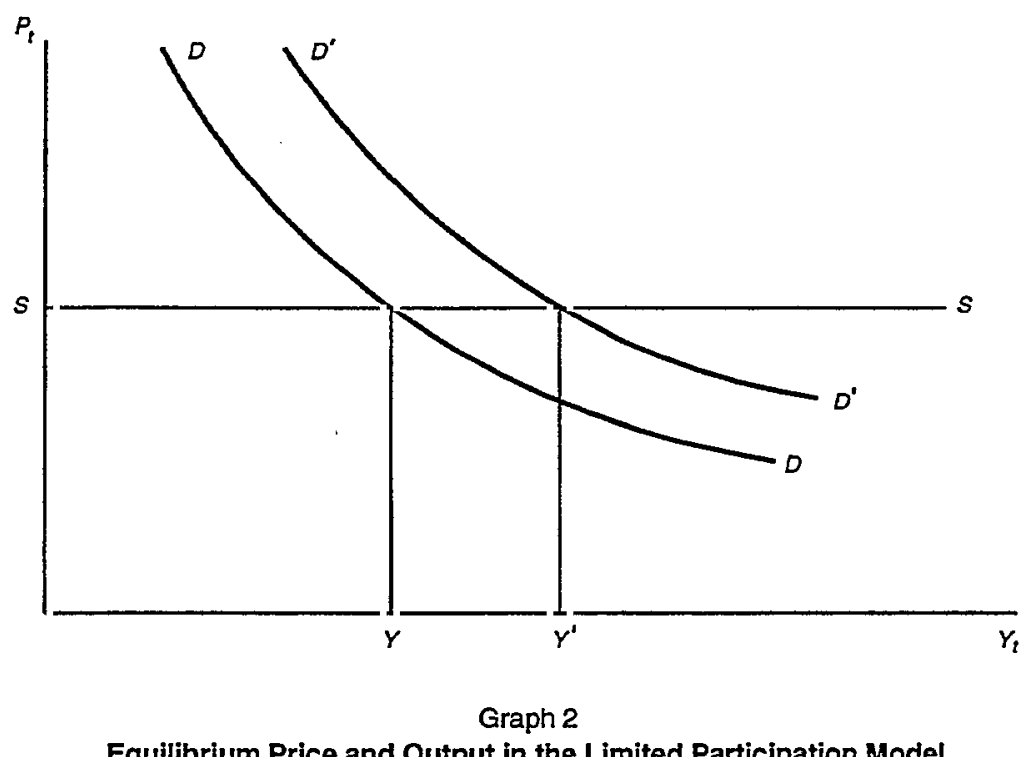

Equilibrium Price and Output in the Limited Participation Model

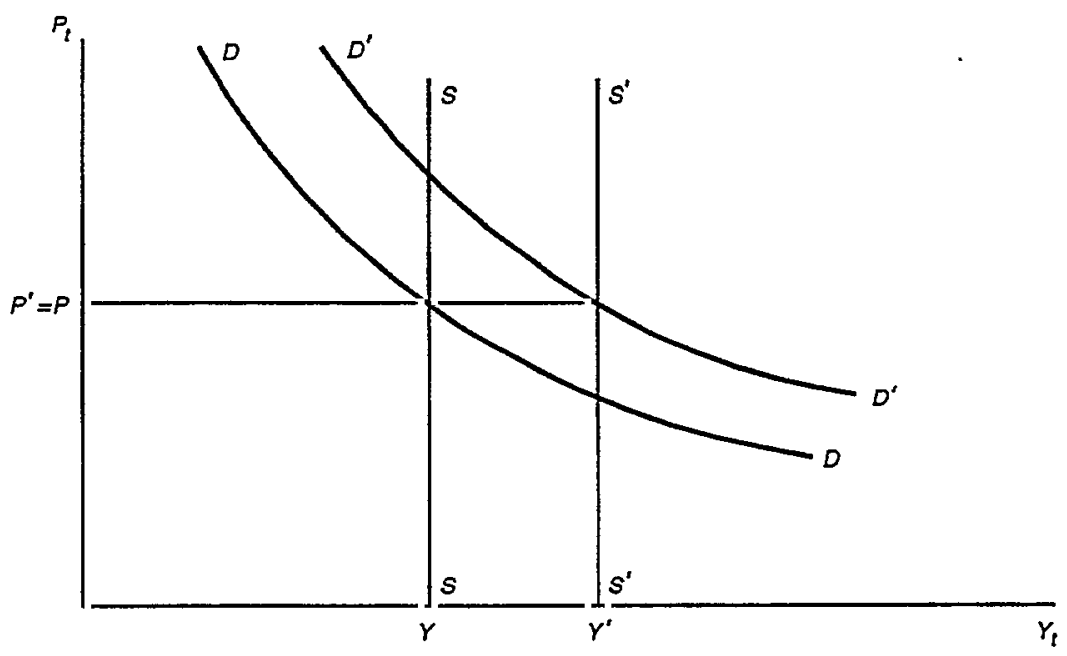

Graph 3

Equilibrium Real Wage and Employment in the Limited Participation Model

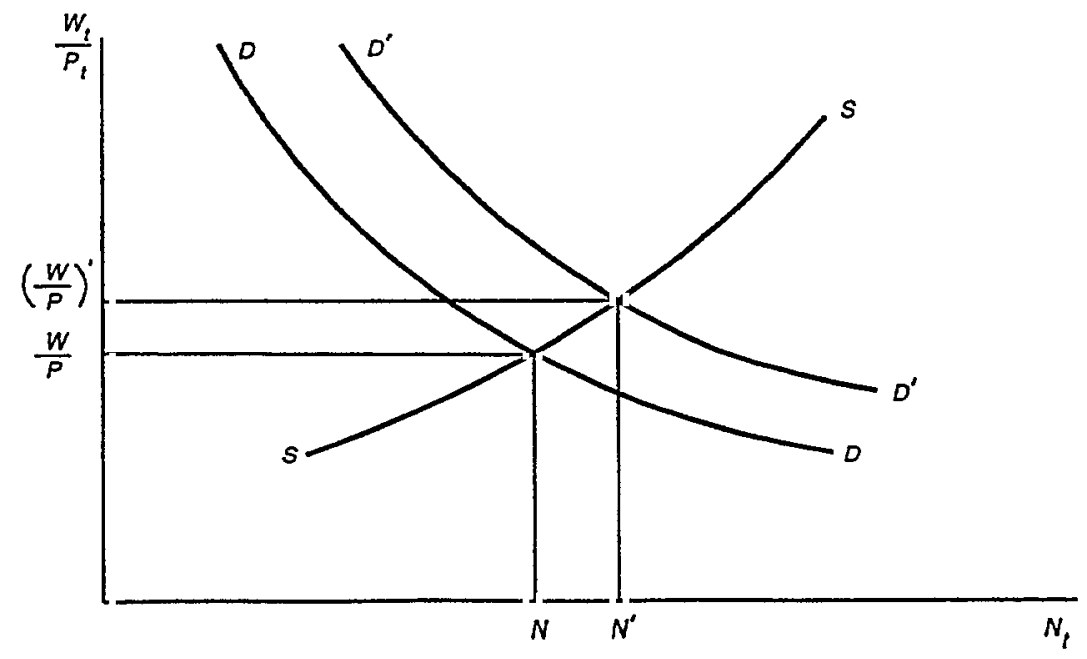



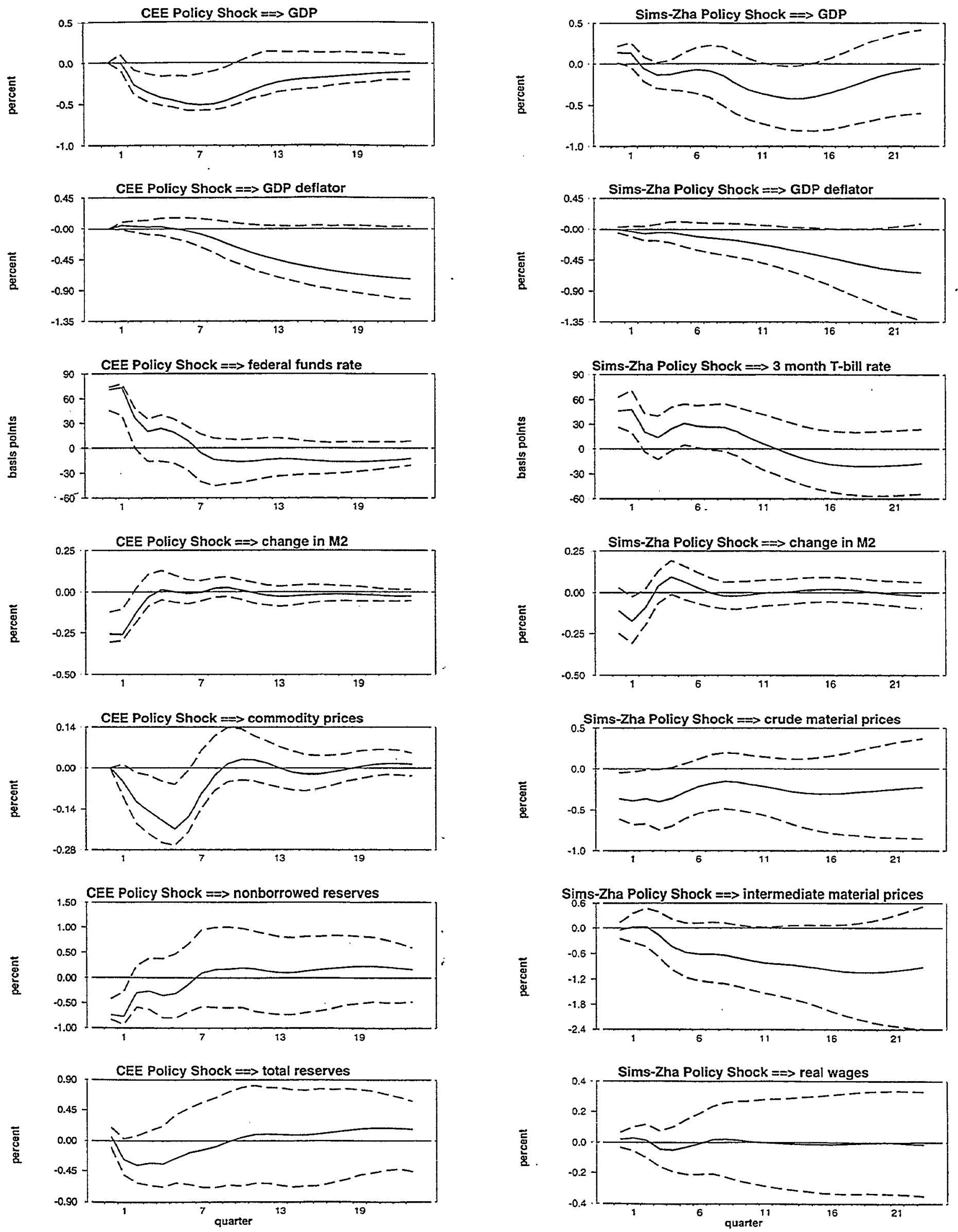


\section{Aggregate Real Wage Responses to Policy Shocks \\ CEE \\ SIMS-ZHA}

Private nonagricultural sector wage deflated by GDP

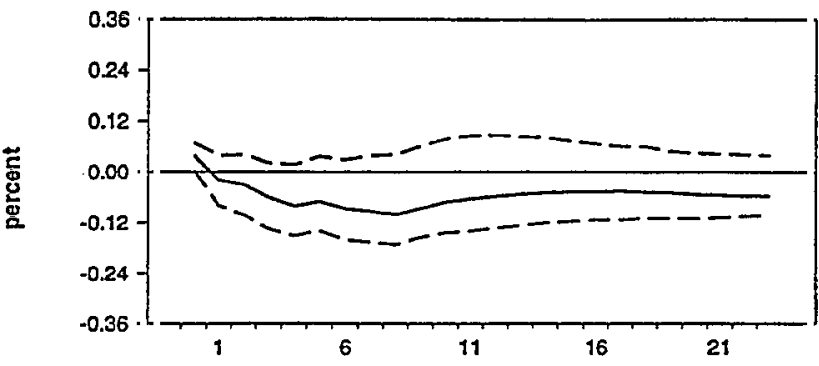

Average hourly earnings deflated by CPIU - wage earners

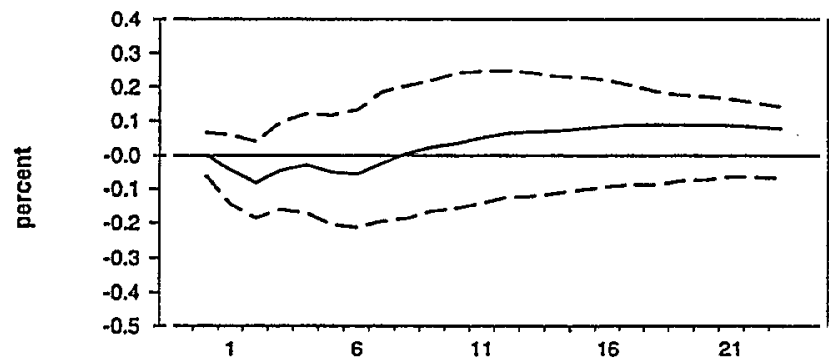

Manufacturing wage deflated by GDP

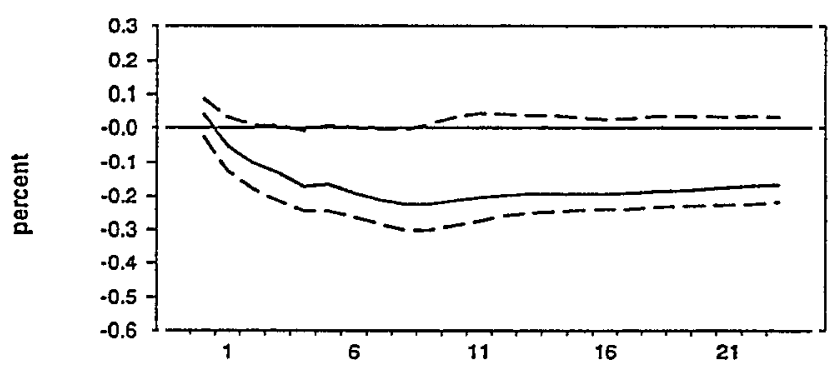

Durable goods wage deflated by GDP

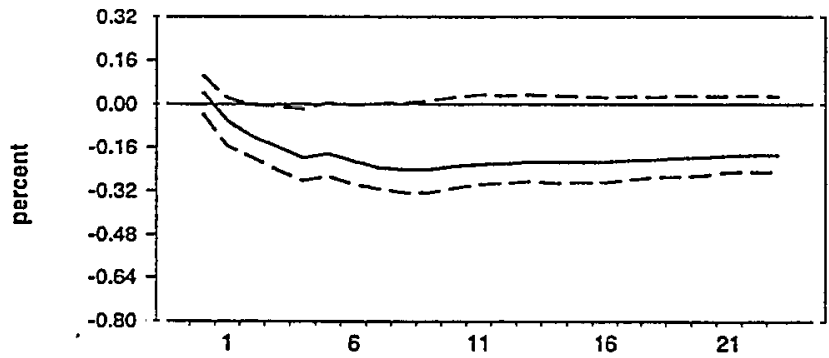

Nondurable goods wage deflated by GDP

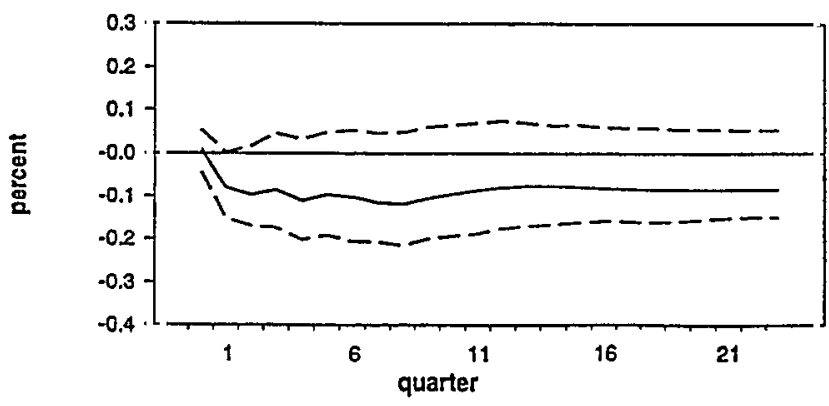

Private nonagricultural sector wage deflated by GDP

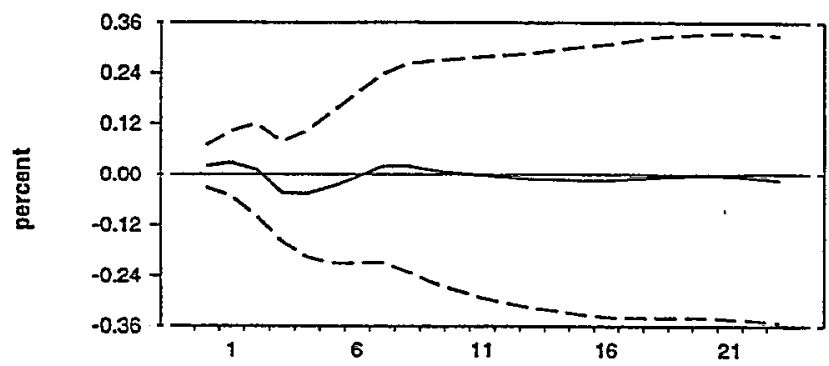

Average hourly earnings deflated by CPIU - wage earners

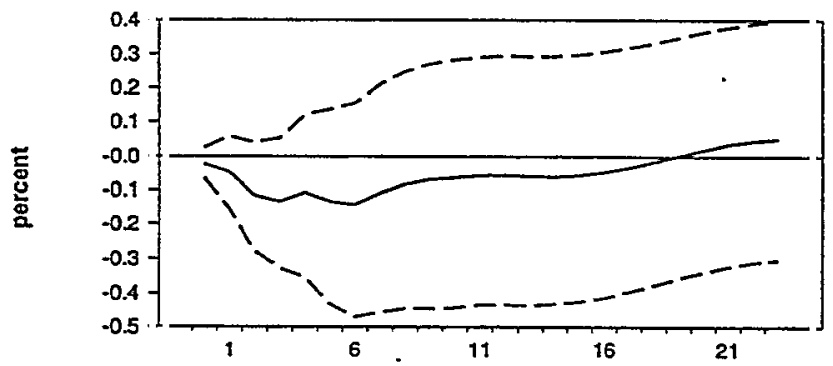

Manufacturing wage deflated by GDP

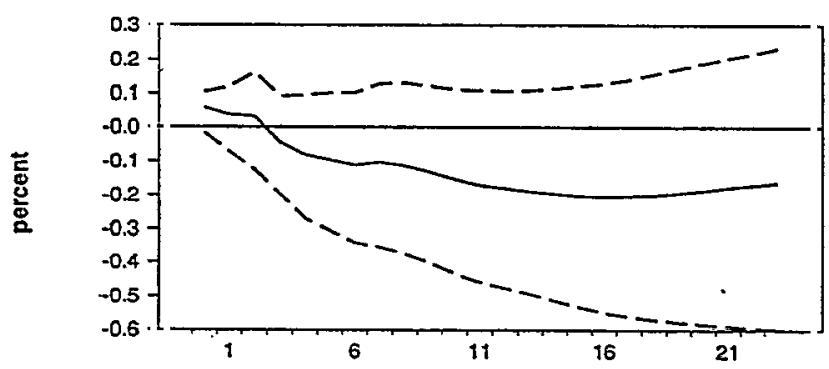

Durable goods wage deflated by GDP

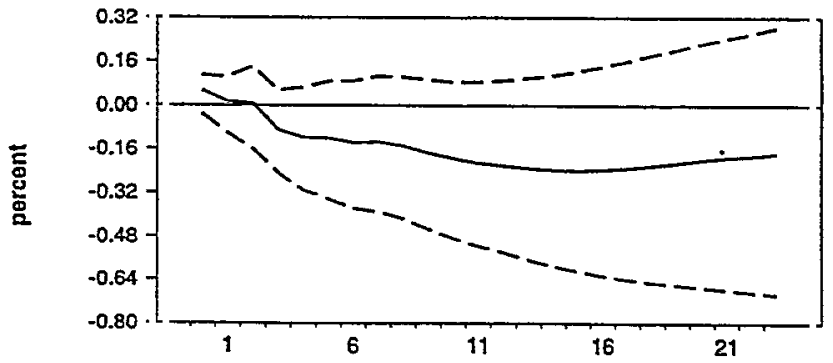

Nondurable goods wage deflated by GDP

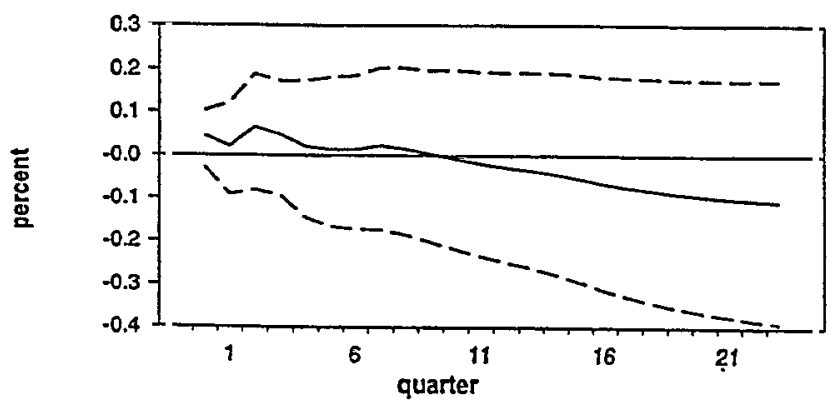


Two-Digit Nondurable Good SIC Real Wage Responses to CEE Policy Shocks

Food and Kindred Products

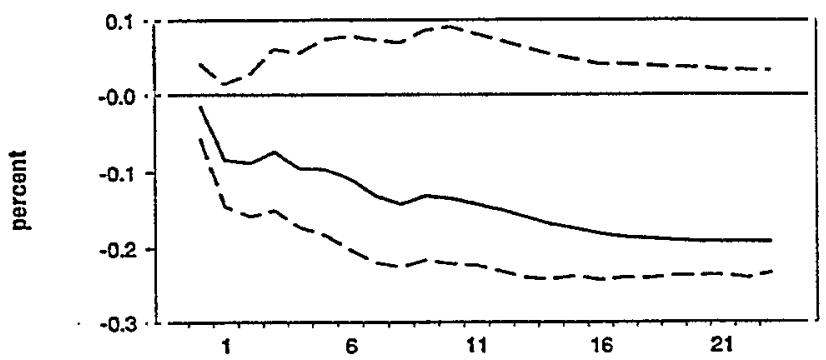

Tobacco

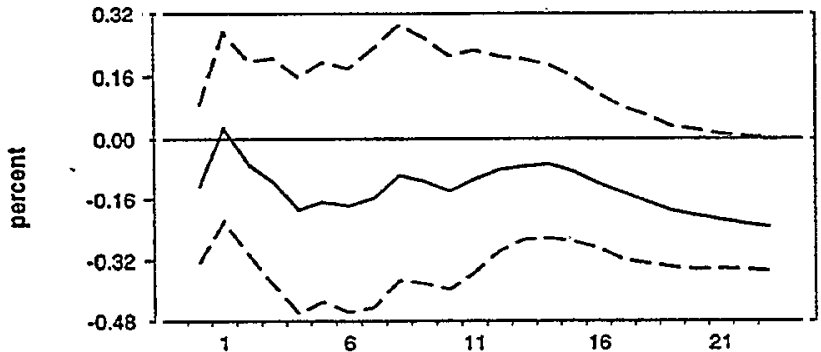

Textile Mill Products

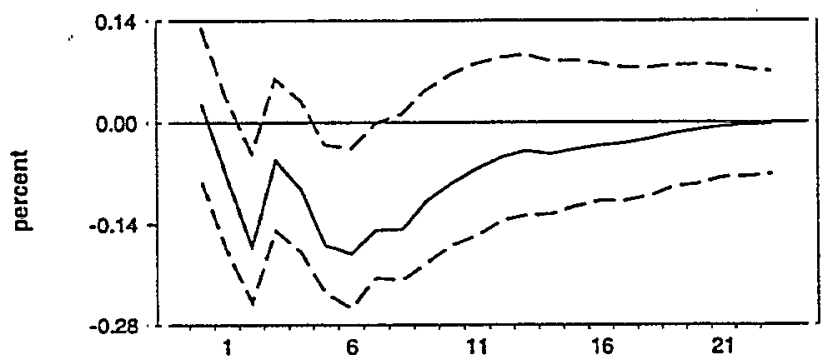

Apparel and other Textiles

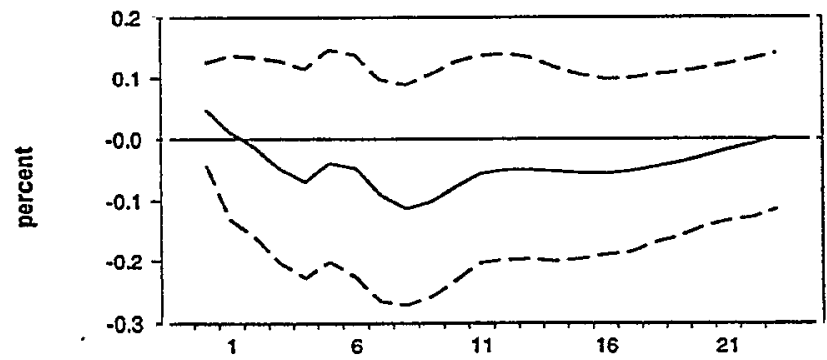

Paper and Allied Products

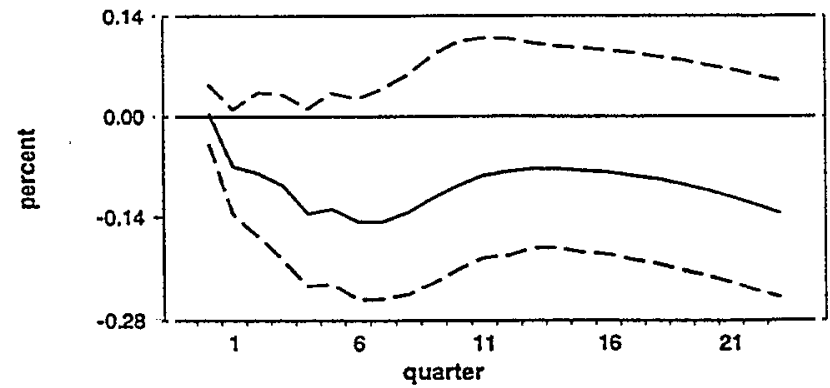

Printing and Publishing

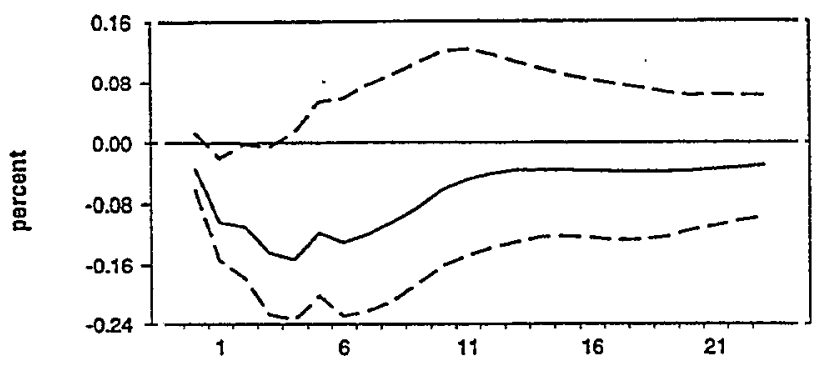

Chemicals and Allied Products

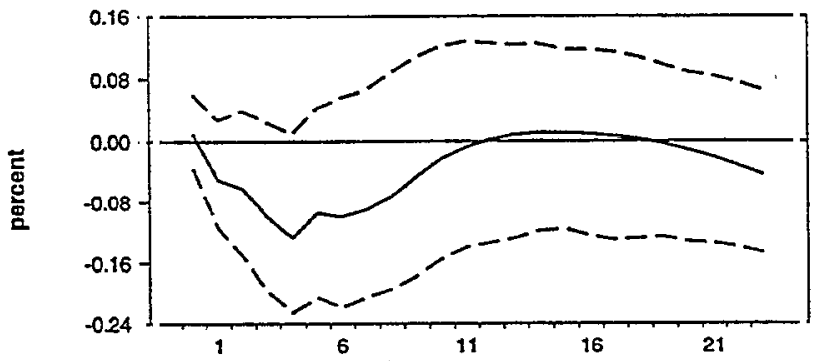

Petroleum and Coal

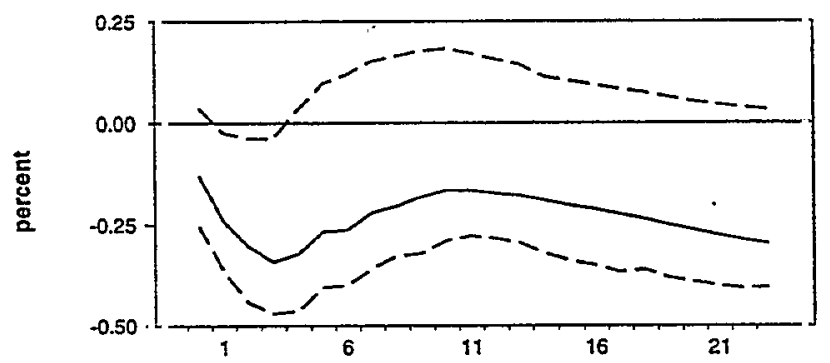

Rubber and Miscellaneous Plastic Products

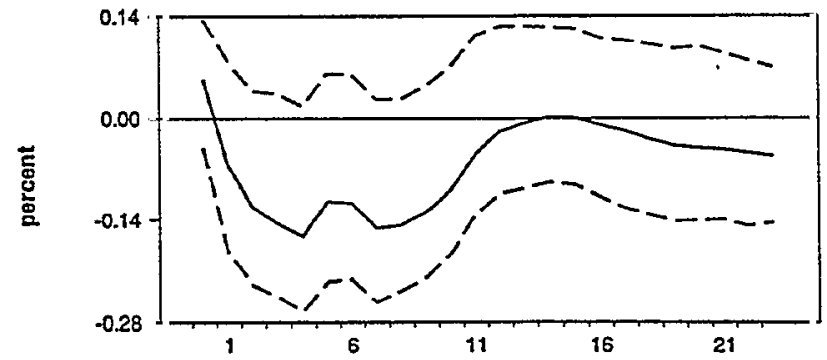

Leather and Leather Products

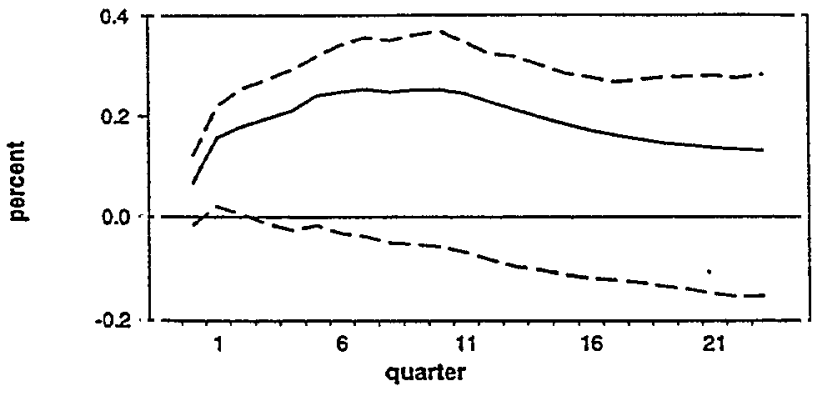


Two-Digit Nondurable Good SIC Real Wage Responses to SZ Policy Shocks

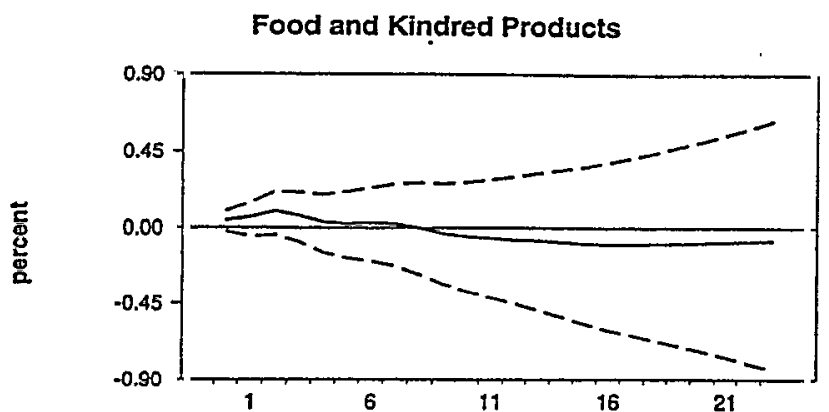

Tobacco

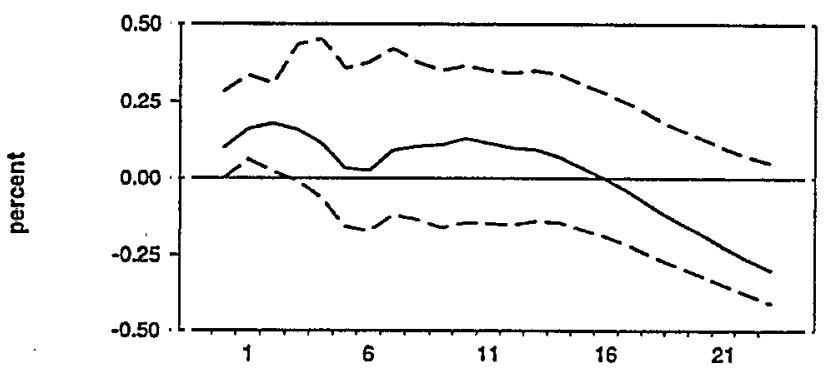

Textile Mill Products

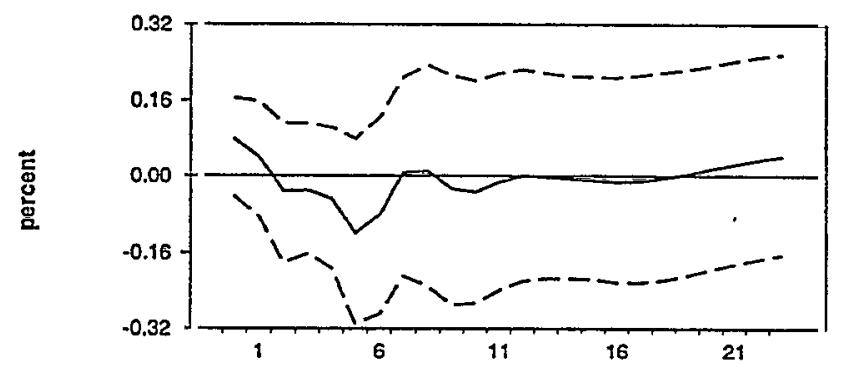

Apparel and other Textiles

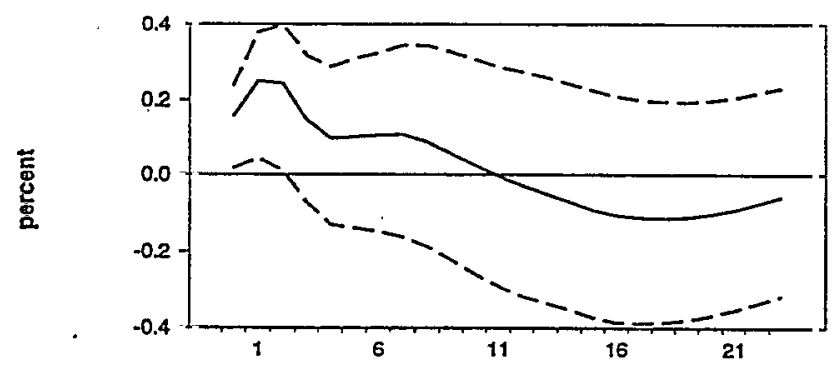

Paper and Allied Products

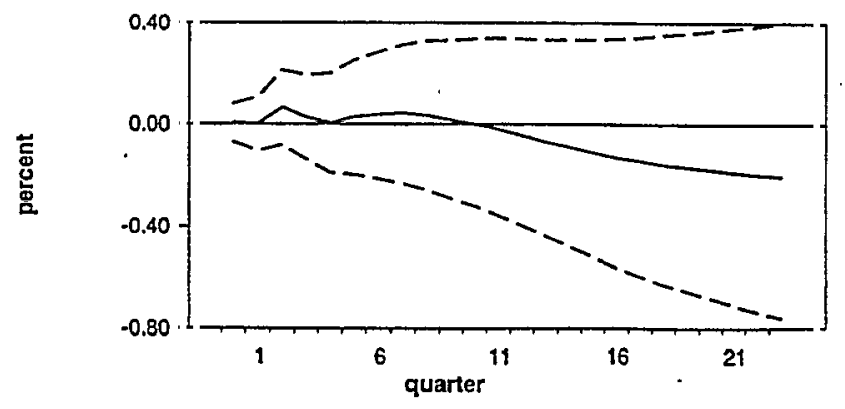

Printing and Publishing

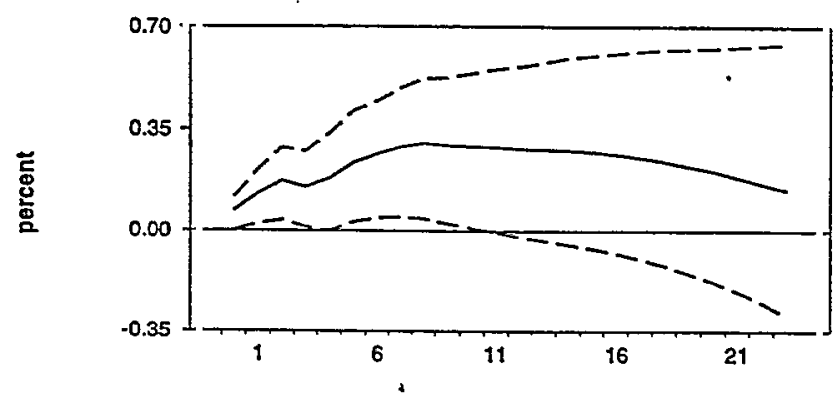

Chemicals and Allied Products

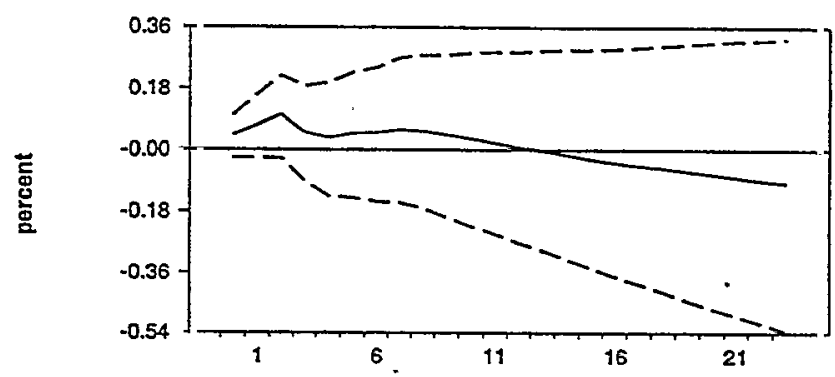

Petroleum and Coal

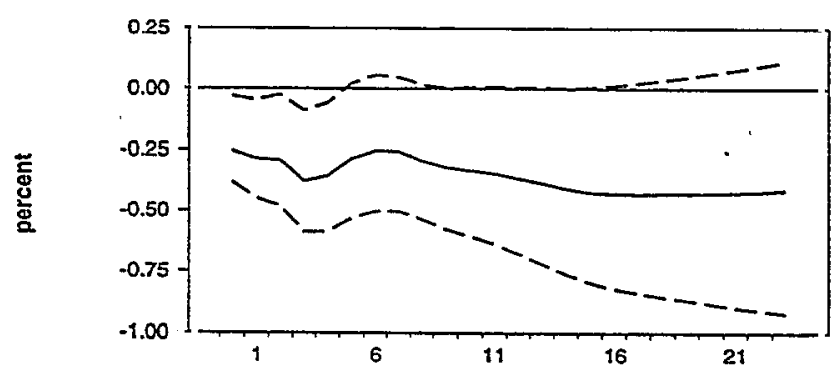

Rubber and Miscellaneous Plastic Products

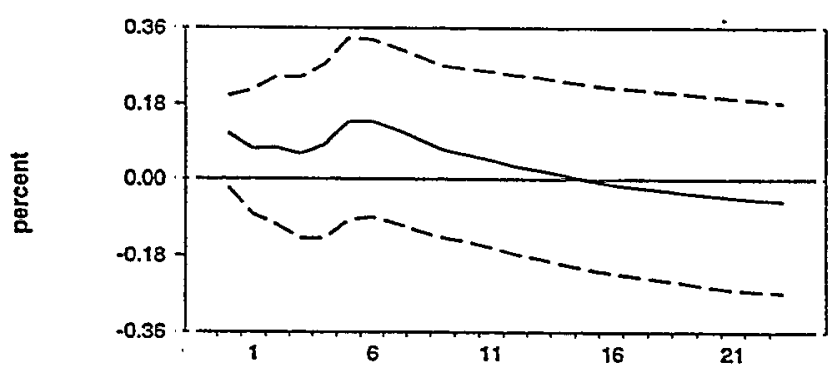

Leather and Leather Products

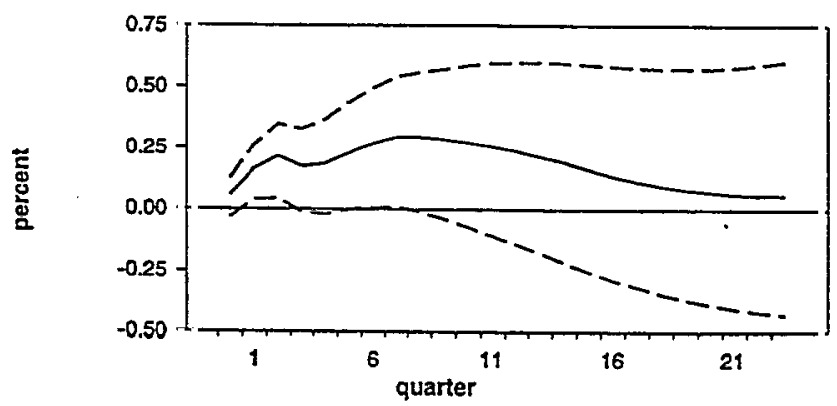




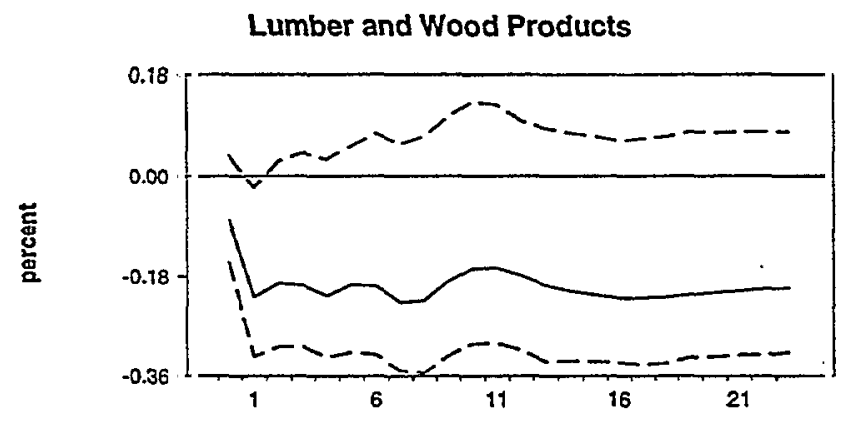

Furniture and Fixtures

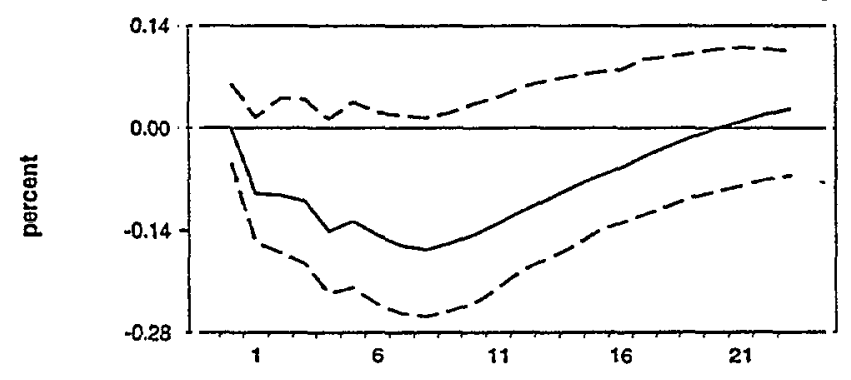

Stone, Clay, and Glass

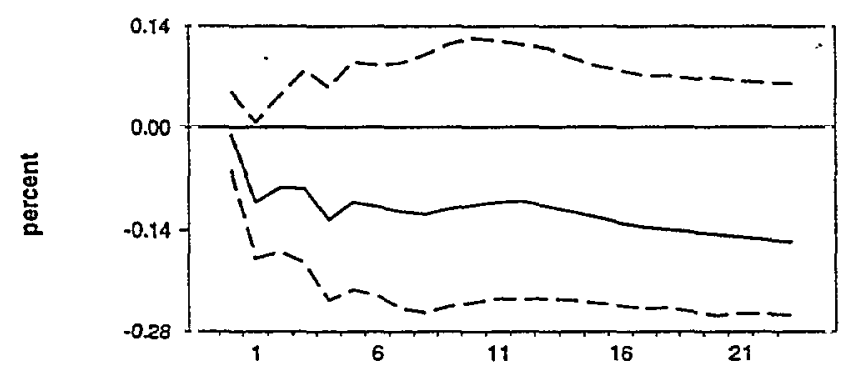

Primary Metal Industries

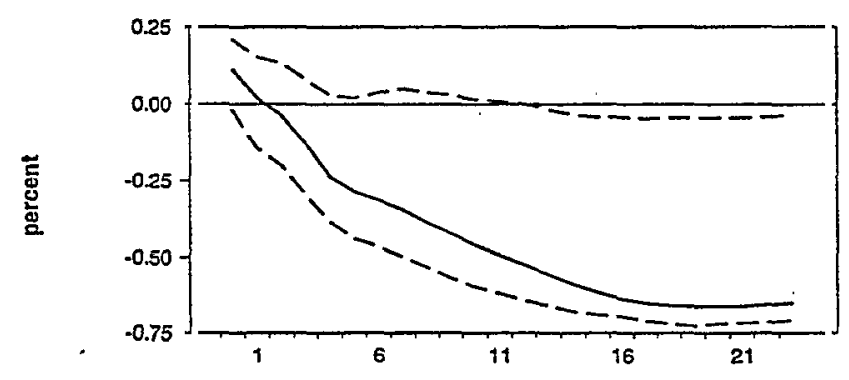

Fabricated Metal Industries

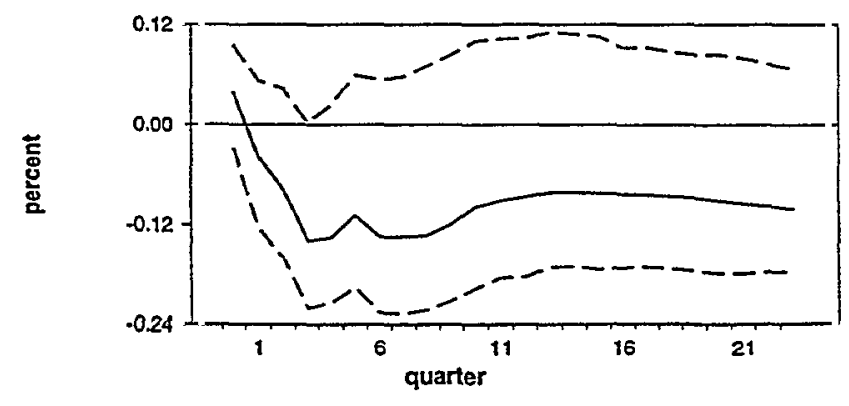

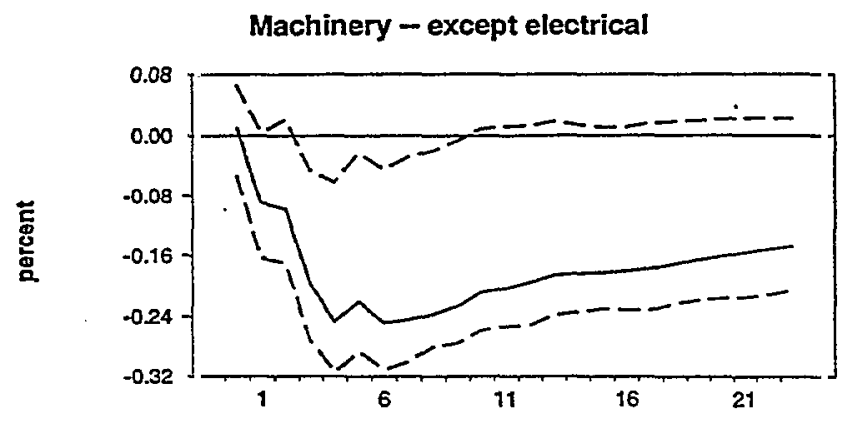

Electric and Electronic Equipment

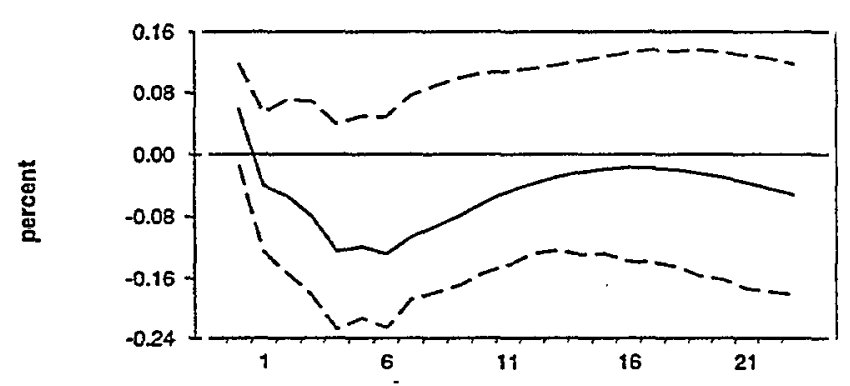

Transportation Equipment

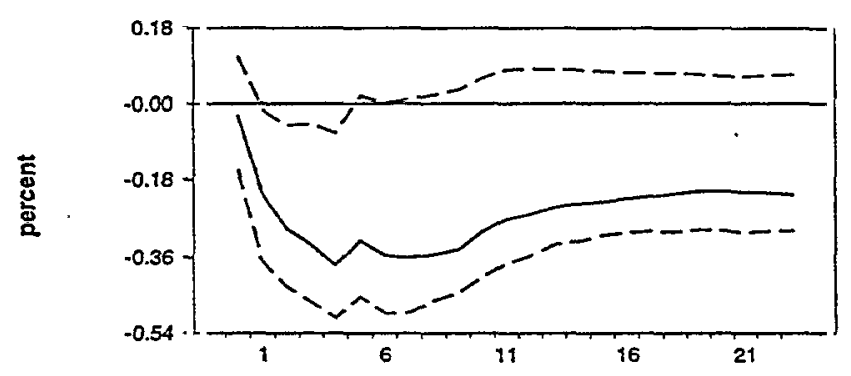

Instruments and Related Products

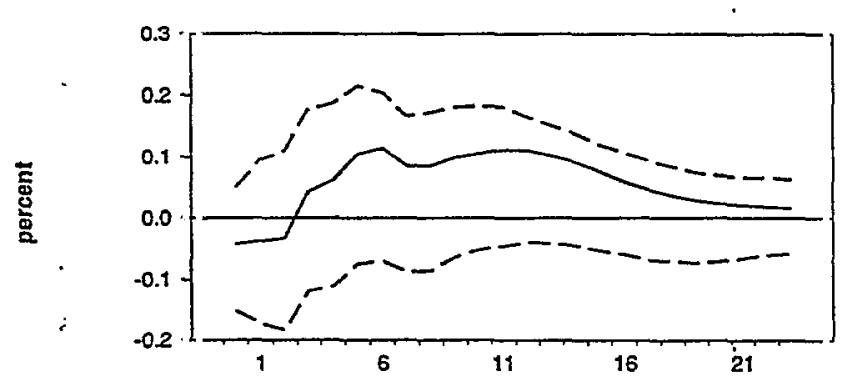

Miscellaneous Manufacturing

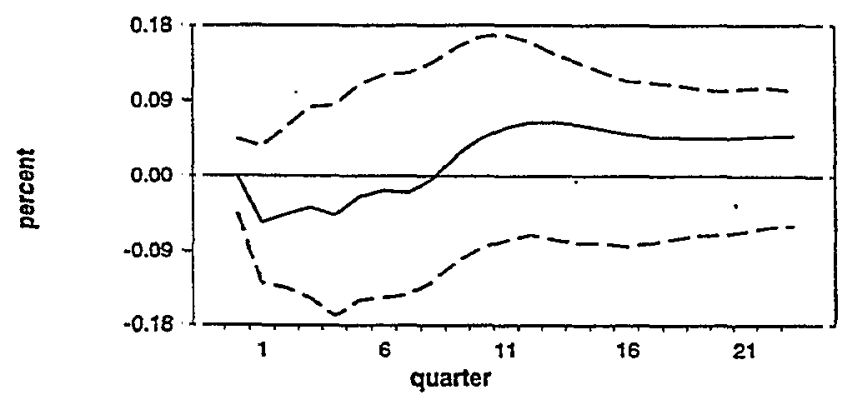




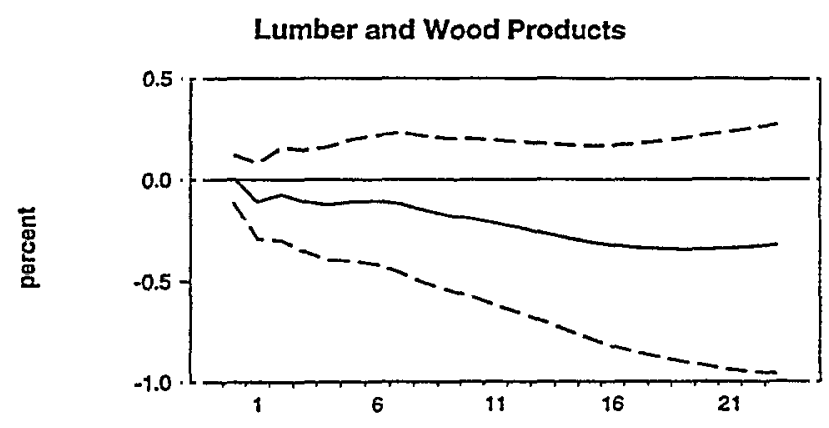

Furniture and Fixtures

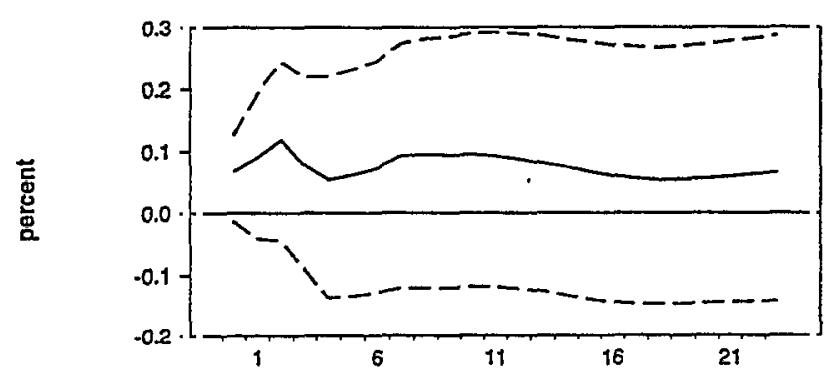

Stone, Clay, and Glass

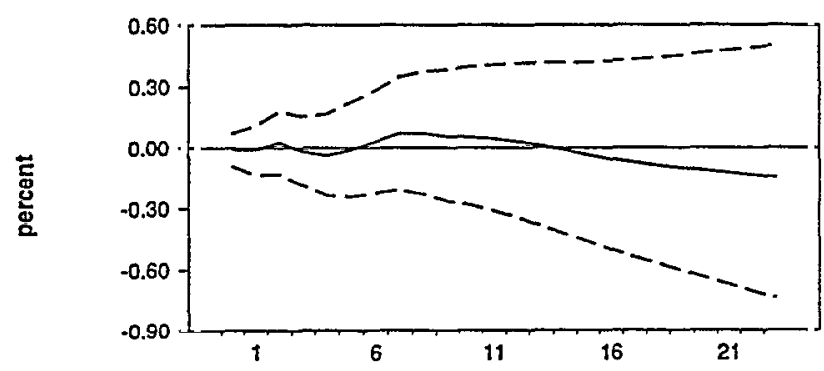

Primary Metal Industries

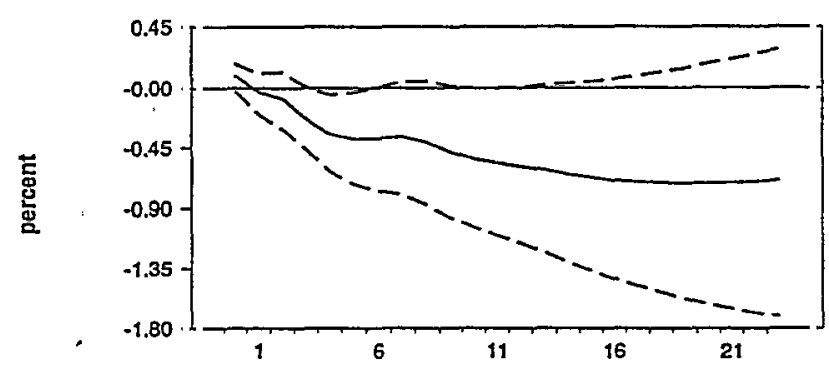

Fabricated Metal Industries

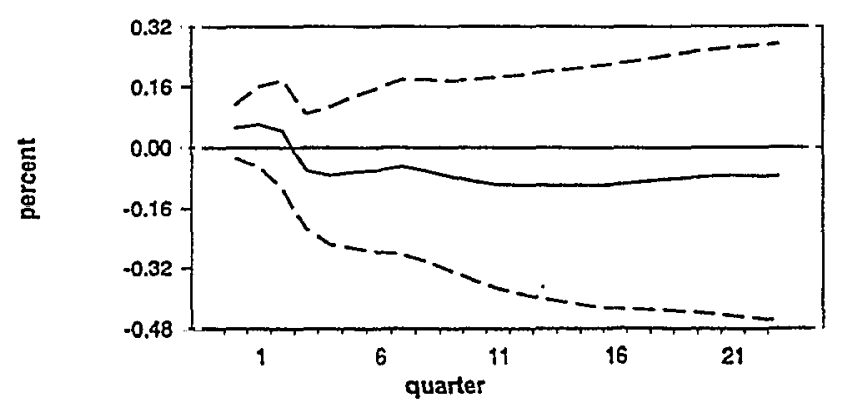

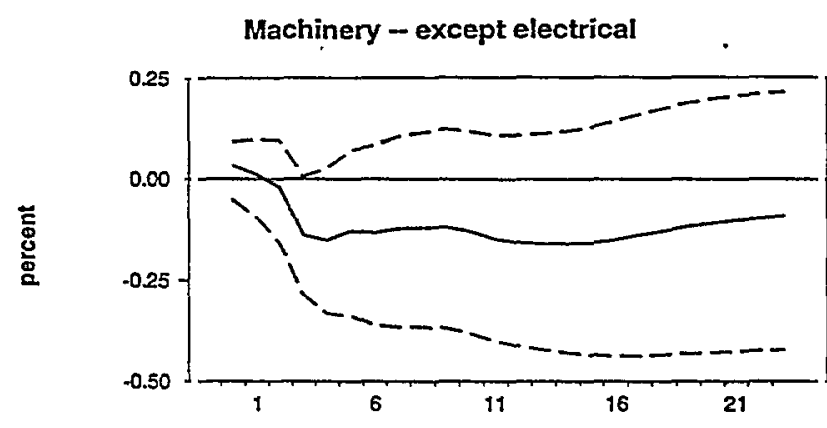

Electric and Electronic Equipment

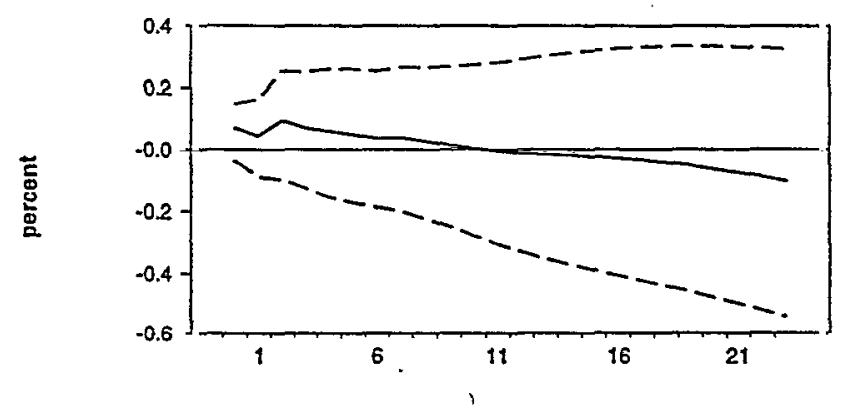

Transportation Equipment

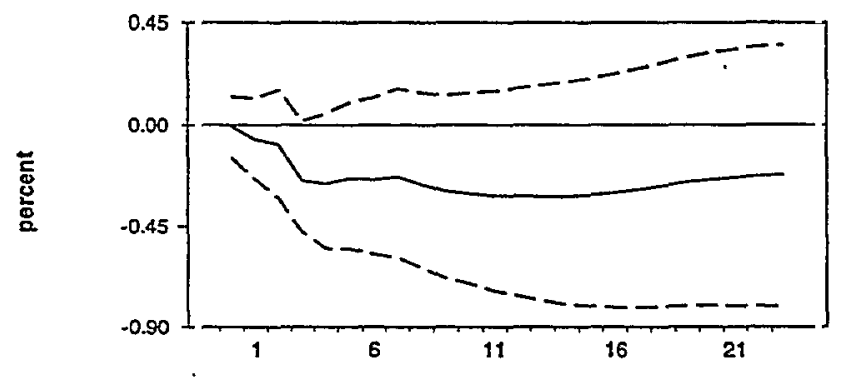

Instruments and Related Products

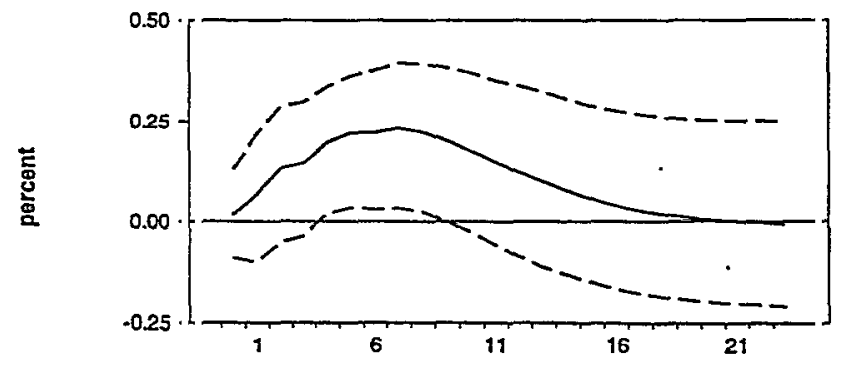

Miscellaneous Manufacturing

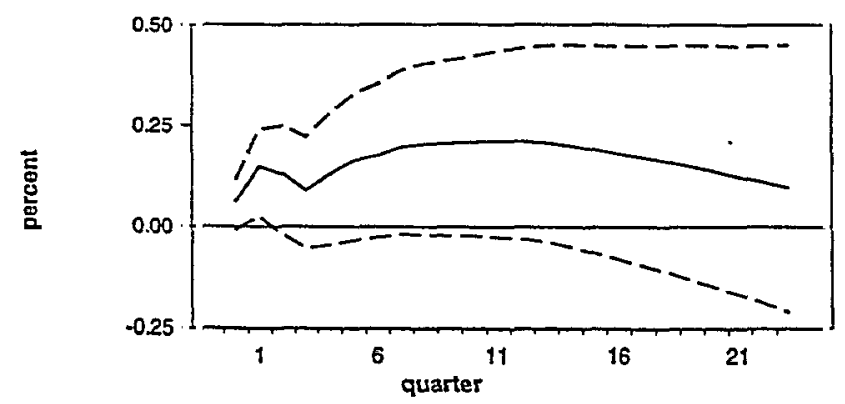


Figure 7

\section{Aggregate Profit Responses to Policy Shocks CEE}

Total profits before taxes

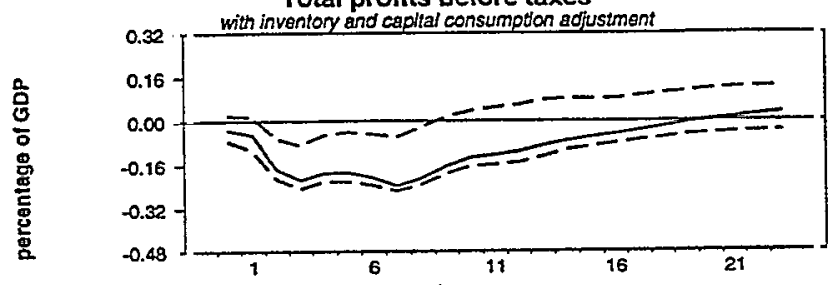

Total profits after taxes

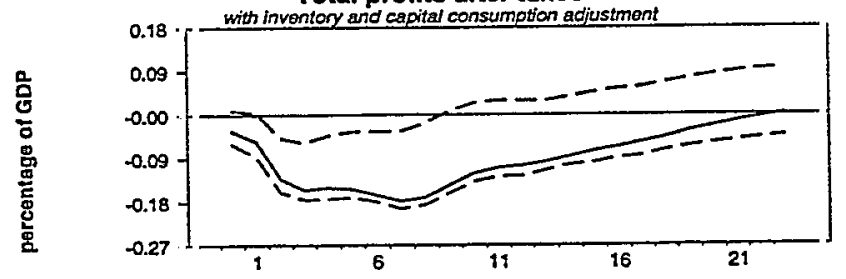

Net domestic profits after taxes

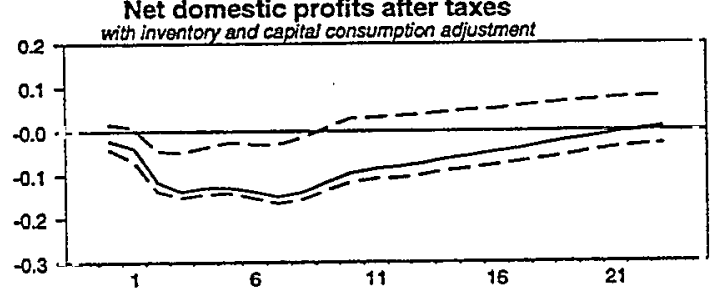

Nonfinancial net domestic profits after taxes

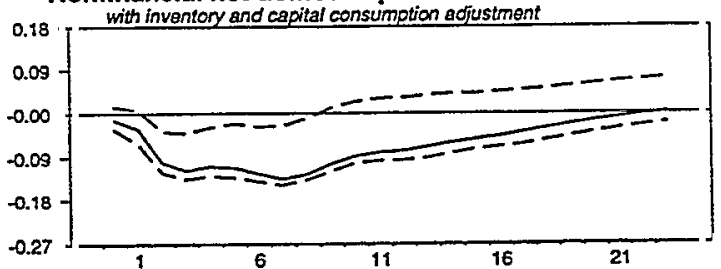

Total profits excluding net interest costs

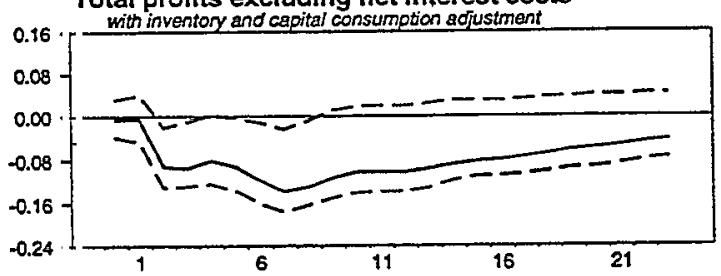

Net domestic profits excluding net interest costs

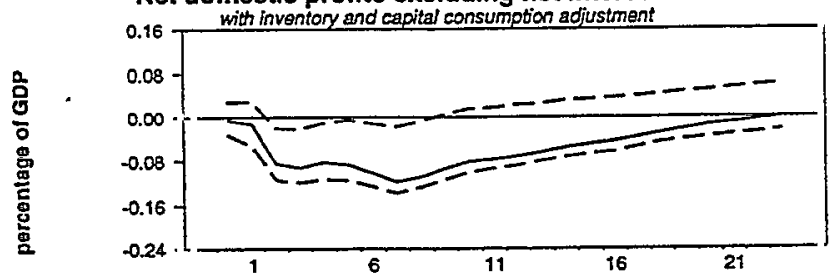

Nonfinancial net domestic profits excluding net interest costs

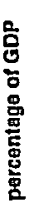

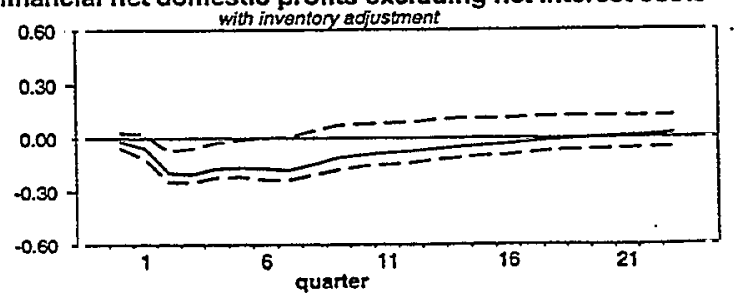

Total profits before taxes

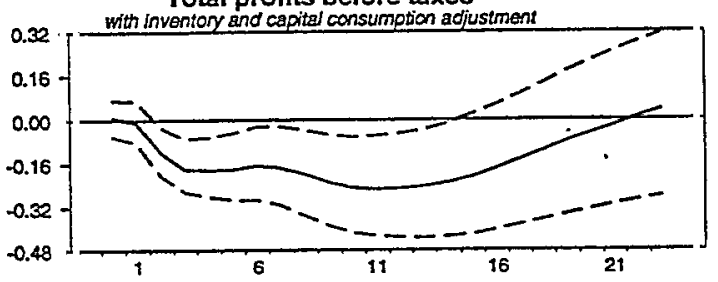

Total profits after taxes

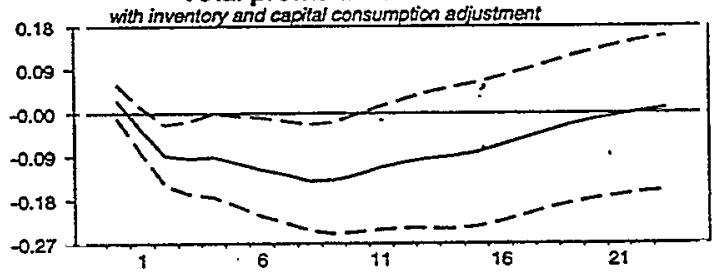

Net domestic profits after taxes

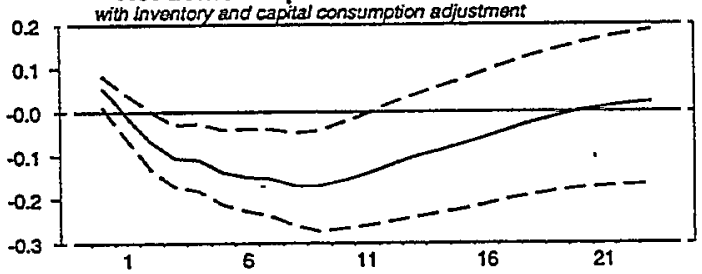

Nonfinancial net domestic profits after taxes

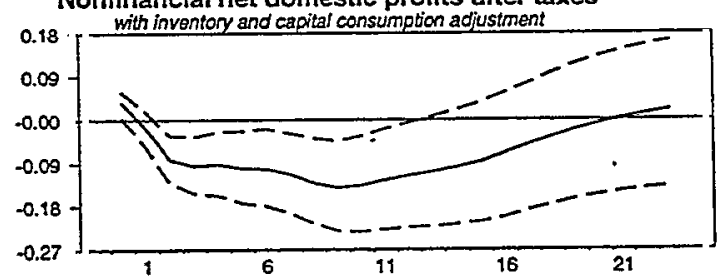

Total profits excluding net interest costs

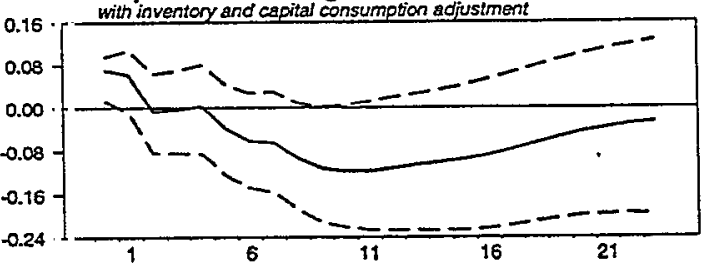

Net domestic profits excluding net interest costs

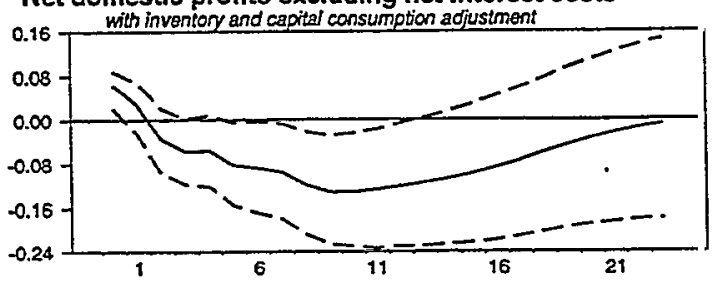

Nonfinancial net domestic profits excluding net interest costs

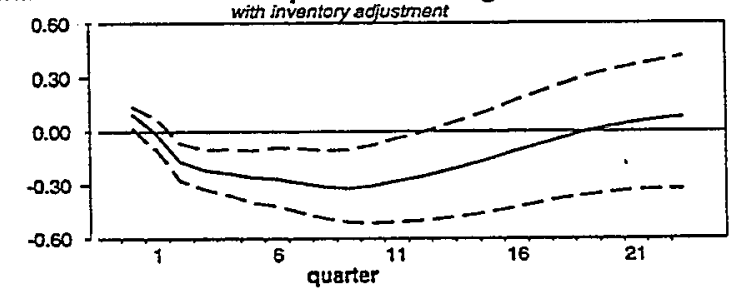


Figure 8

Sectoral Profit Responses to Policy Shocks

CEE

Manufacturing

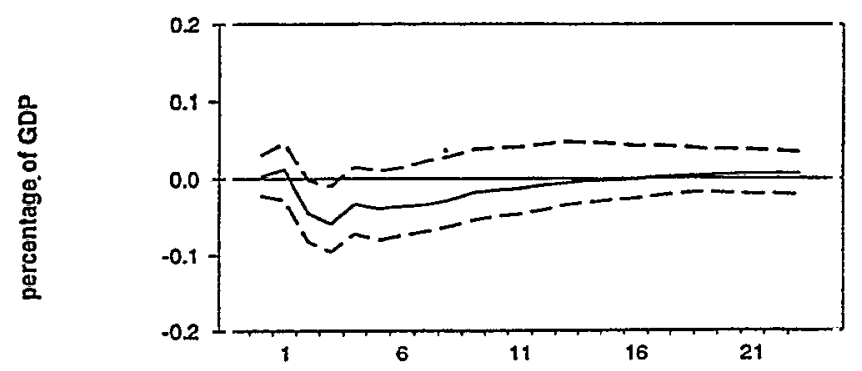

Nondurables

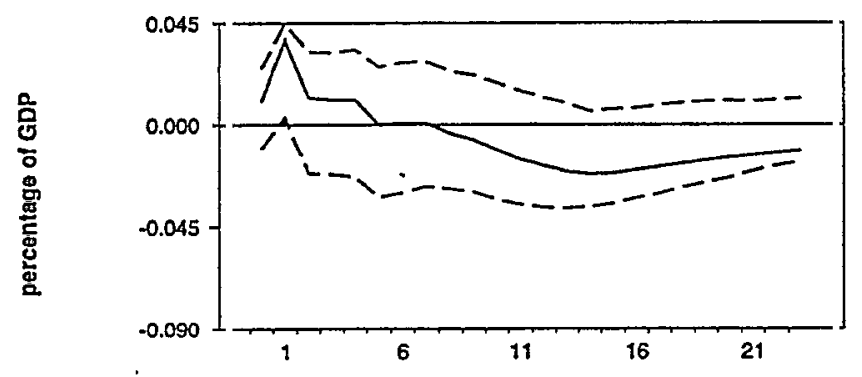

Durables

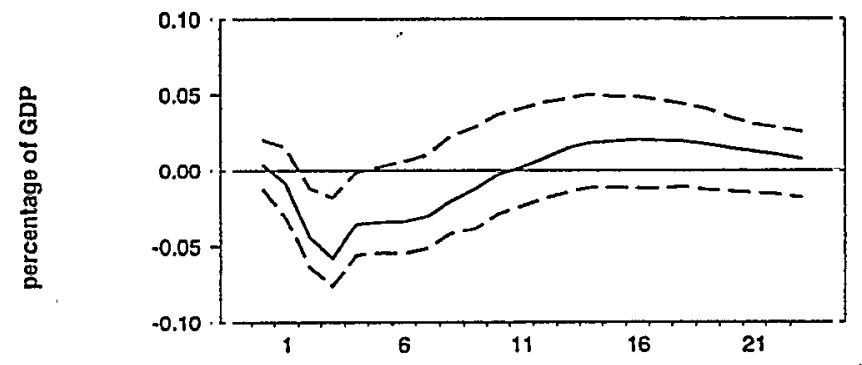

Retail

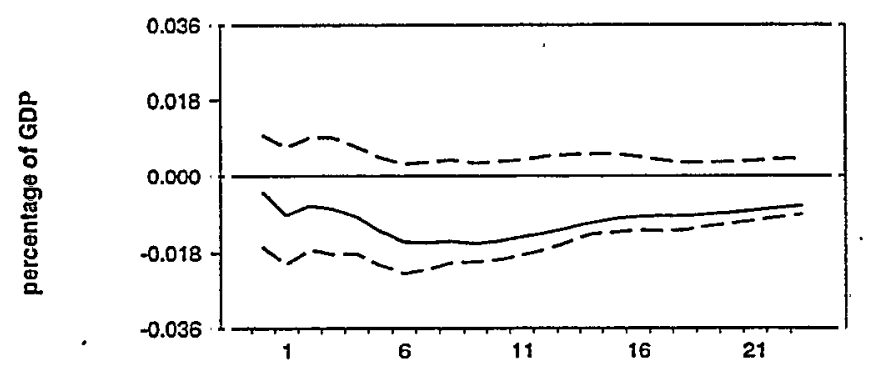

Transportation \& Utilities

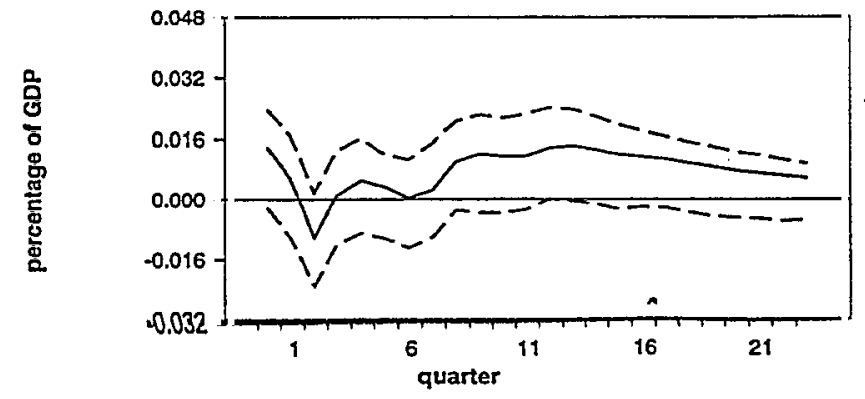

SIMS-ZHA

Manufacturing

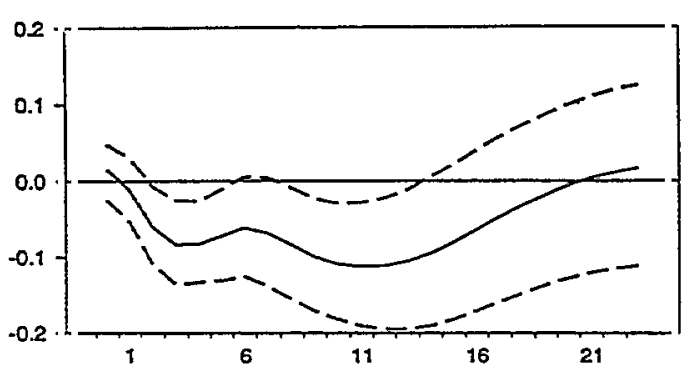

Nondurables

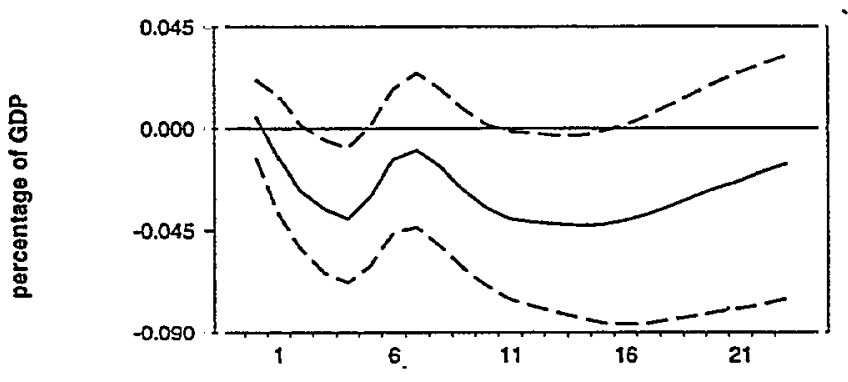

Durables

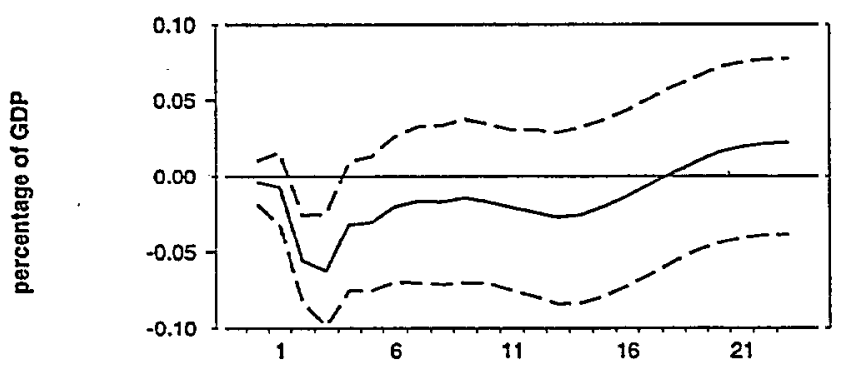

Retail

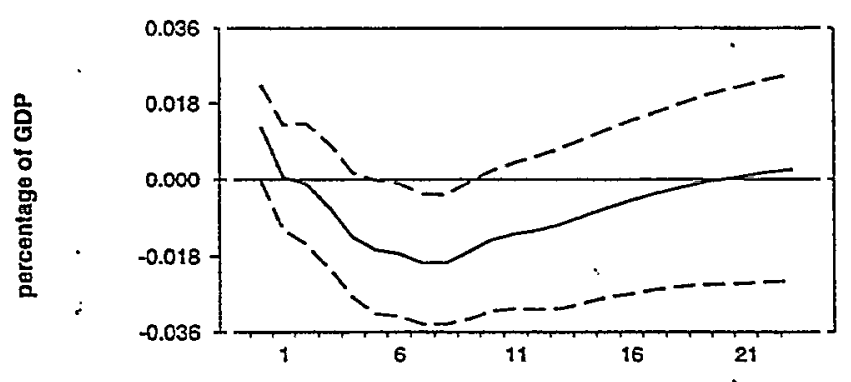

Transportation \& Utilities

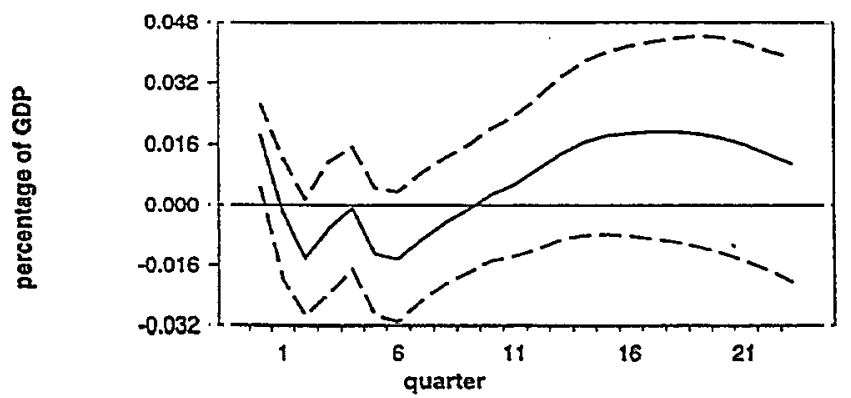




\section{Figure 9}

\section{Sequence of Events in Period $t$ in the Two Models}

\section{Sticky Price Model}

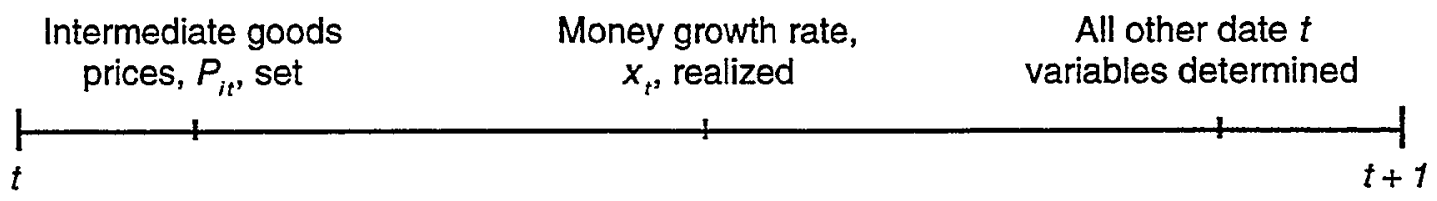

\section{Limited Participation Model}

Household deposit with financial intermediary, $l_{t}$, set
Money growth rate, $x_{t}$, realized
All other date $t$ variables determined

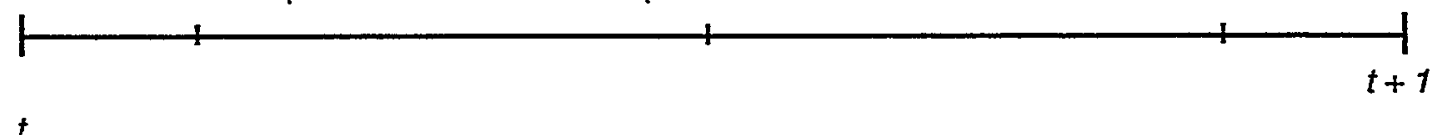

